Review Article

\title{
HIGHLIGHTS ON ARTIFICIAL INSEMINATION (AI) TECHNOLOGY IN THE PIGS
}

\author{
Tarek Khalifa ${ }^{1,2}$, Constantinos Rekkas ${ }^{2}$, Foteini Samartzi², \\ Aristotelis Lymberopoulos ${ }^{3}$, Kostas Kousenidis ${ }^{3}$, Toni Dovenski ${ }^{4}$ \\ ${ }^{1}$ EquiBiotech Inc-Research Services in Farm Animal Breeding, \\ 19 Gravias Street P.O. Box 54645, Thessaloniki, Greece \\ ${ }^{2}$ Veterinary Research Institute, Hellenic Agricultural Organization, \\ 57001 NAGREF Campus, Thermi, P.O. Box 60272, Thessaloniki, Greece \\ ${ }^{3}$ Alexander Technological Educational Institute, Department of Animal Production, \\ P.O. Box 141 Sindos, Thessaloniki, Greece
}

${ }^{4}$ Ss. Cyril and Methodius University in Skopje, Faculty of Veterinary Medicine, Institute of Reproduction, Lazar Pop Trajkov 5-7, 1000 Skopje, R. Macedonia

Received 7 September 2013; Accepted 30 September 2013

\begin{abstract}
Over the past decade, there has been a tremendous increase in the development of field AI services in the majority of countries concerned with pig production. The objective of this paper is to review: (a) the current status of swine AI in the world, (b) significance and limitation of AI with liquid and frozen semen, (c) the biological traits of porcine semen in relation to in vitro sperm storage, (d) the criteria used for selection of a boar stud as a semen supplier, (e) how to process boar semen for liquid and frozen storage in the commercial settings and (f) how to improve fertility and prolificacy of boar semen. More than $99 \%$ of the inseminations conducted worldwide are made with liquid-stored semen. AI with frozen semen is used only for upgrading the genetic base in a particular country or herd. Determining the initial quality of semen ejaculates along with the selection of the optimum storage extender has a profound effect on the quality and fertility of AI doses. Different procedures have been used for improving the fertility of preserved spermatozoa including colloidal centrifugation of the semen, intrauterine insemination and modulation of the uterine defense mechanism after AI. Development of an efficient protocol for synchronizing the time of ovulation in sows and gilts coupled with improving uterine horn insemination technique will make a breakthrough in the commercial use of frozen boar semen.
\end{abstract}

Key words: boar; semen storage; artificial insemination; fertility

\section{INTRODUCTION}

AI is of great economic value for the pig industry. In the past two decades, there has been an enormous increase in the development of field AI services in the majority of countries concerned with pork production. In the authors' opinion, several deciding factors have paved the way for many producers to use AI in the breeding management programs (1). First, the industry's requirement for improved leanness and maternal traits has stimulated the need

Corresponding author: Dr. Tarek Khalifa, $\mathrm{PhD}$

E-mail address: drtarekkhalifa@gmail.com

Present address: EquiBiotech Inc-Research Services in

Farm Animal Breeding;

19 Gravias street 54645, Thessaloniki, Greece

Tel: +30 2310 869500/Mob: +30 6984979261

Copyright: $\odot 2014$ Khalifa T. This is an open-access article published under the terms of the Creative Commons Attribution License which permits unrestricted use, distribution, and reproduction in any medium, provided the original author and source are credited.

Competing Interests: The authors have declared that no competing interests exist.

Available Online First: 15 November 2013

http://dx.doi.org/10.14432/j.macvetrev.2013.09.001 for changes in genetic programs, and AI provides a viable tool for this change. Second, increased understanding of the merits of utilizing sires with predictable superior genetics. Third, favorable field results have been reported after AI with liquid-stored semen. Fourth, on-farm AI as compared with natural service can provide substantial economic benefits, especially in larger production units. Fifth, semen is available from a number of commercial sources at a competitive price. Sixth, AI technique is simple to learn and the equipment cost is reasonable.

More than $99 \%$ of inseminations conducted worldwide are made with liquid-stored semen at $15-20^{\circ} \mathrm{C}$ for $0-5$ days, with $85 \%$ of all inseminations are carried out on the day of collection or on the following day for meat production market. Less than $1 \%$ of all inseminations are made with cryopreserved semen for upgrading the genetic nucleus in a particular country or herd. 
The commercial use of liquid-stored semen includes do-it-yourself AI (DIY AI; pig producers collect semen and inseminate the females on their own farm, i.e. on-farm semen collection, processing and AI) and extensive networks of AI centers with services set up to deliver the semen (2). The numbers of AI centers in Germany, Spain, Denmark, Poland, Belgium, Sweden and Norway are 22, 74, 13, 22, 37,3 and 1, respectively ( 172 centers in Europe). AI with liquid-stored semen has reached a very high level in USA and Mexico at $~ 90 \%$ and in Canada at $80 \%$. In South American countries, pig production has greatly increased as a total in the last decade (Brazil, Argentina and Chile by 450, 112 and 65\%, respectively). This features an extremely high AI level with almost $100 \%$ in Chile and $66 \%$ in Brazil. China represents an example for the increases in pig production, with $\sim 33$ million tons of pork have been produced in China in 1996. In 2008, production was more than 47 million tons. During the next years, further growth of pork production is predicted in China and Brazil (3).

\section{LEARNING OBJECTIVES}

The aim of the present review is to shed some light on the porcine AI industry. By the end of this review, the reader should be able to understand: (a) the current status of swine AI in the world, (b) significance and limitation of AI with liquid and frozen semen, (c) the biological traits of porcine semen in relation to in vitro sperm storage, (d) the criteria used for selection of a boar stud as a semen supplier, (e) how to process boar semen for liquid and frozen storage in the commercial settings, and (f) how to improve fertility and prolificacy of boar semen after AI.

\section{Structure of AI industry in some countries of the world}

\section{North American AI centers}

Boar studs with 100-500 sires are most common in Canada and USA. Most boars are housed in stalls and fed according to their body condition or weight. The predominant age of boars is 1-2 years. Evaporative and mechanical systems are the predominant methods of thermal control. The annual boar replacement (culling) rates ranges between 20 and $70 \%$. The primary reasons for culling include genetic improvement, semen quality and feet and leg problems. Training of boars for semen collection is initiated at 8-9 months of age and requires 1-3 weeks to complete. Collection occurs commonly on Monday and Thursday and boars are rested 3-7 days between collections. Most studs utilize double gloves with the outer pair discarded prior to semen collection. The most common type of collection containers used is a disposable bag inside a thermal container. Pre-warming collection containers is practiced by $75 \%$ of studs. The average sperm produced/boar/ week is 51-150 billions resulting in 21-40 doses/ boar/week. Ejaculate pooling is performed in $60 \%$ of studs, using 2-3 or 4-6 ejaculates. Evaluation of semen for sperm motility is done within $0-5$ min of warming in an extender with viewing at $100-400 \times$ magnification. Sperm concentration is determined by photometers and CASA for $88 \%$ of studs. Ejaculates are discarded most frequently at a rate of $1-10 \%$ due to poor motility, abnormal sperm morphology, bacteriospermia and other factors involving low sperm concentration, low semen volume, presence of contaminants such as blood, urine and off odor or abnormal color of semen. The majority of discards occur as a result of individual boar and season. Semen culture for bacterial growth in ejaculates is performed routinely on set schedules in $84 \%$ of studs, and only in cases of problems for $14 \%$ and is not performed in $2 \%$ of studs. For quality control, most studs maintain semen samples following extension for 3-4 or 3-7 days $(4,5)$.

The majority of studs use proprietary commercial extenders followed by non-proprietary BTS (Beltsville Thawing Solution) extender. The relative contribution of each storage medium to all studs is as follows: 50\% Androhep $^{\circledR}, 30 \% \mathrm{X}$-Cell ${ }^{\circledR}$, $25 \%$ BTS, 20\% Enduraguard ${ }^{\circledR}, 12 \%$ Geddil $^{\mathrm{TM}}$, $10 \%$ Preserv $^{\mathrm{TM}}, 7 \%$ Ivo-Zeist $^{\mathrm{TM}}$ and MR-A ${ }^{\circledR}$, and $3 \% \quad$ Acromax $^{\circledR}$, Cell-Lution ${ }^{\mathrm{TM}}$, Safe-Cell ${ }^{\mathrm{TM}}$, Survivor $^{\mathrm{TM}}$ and Vital ${ }^{\circledR}$. The choice of an extender is based primarily on the duration of preservation for sperm fertility, the cost and the brand recognition in $65 \%, 51 \%$ and $33 \%$ of studs, respectively. When preparing the extender, $74 \%$ of the studs use an inhouse water purification system while $26 \%$ of them purchase purified water. Water quality is tested for impurities by $67 \%$, formicrobes by $58 \%$ oritisreported to occur by assurance of the water manufacturer by $33 \%$ or is reported as unknown by $7 \%$ of studs. Semen is packaged at 2-4 billion fertile sperm 
cells/dose in $>90 \%$ of studs. Of studs, $42 \%$ indicate that they alter the number of sperm in the final packaged dose based on breed or genetic line. For the final sperm numbers in a dose, most studs indicate that they adjust the total cells in the dose based on morphologically normal or viable sperm. For the final packaging, sealed tubes or bags containing 60-80 $\mathrm{ml}$ of diluted semen are used in most studs. Custom processing for packaging or for specific volumes is not a service provided by $81 \%$ of studs, but in those that do, some process for packaging in the GEDIS ${ }^{\circledR}$ device (IMV technologies, France) and others process for frozen semen. Semen delivery is accomplished by stud personnel for $45 \%$ of studs while $36 \%$ of studs use an independent courier and $27 \%$ use another system which includes a company courier that has delivery duties but are not stud related (5).

\section{Dutch AI centers}

In Europe, the pig AI rate is between 25 and 98\%. In The Netherlands, the pig AI rate is 98\%, based on the annual 4.3 million sow matings. About 97\% of the insemination doses are purchased from AI companies of which $90 \%$ through the cooperative pig AI centers Varkens KI Nederland (contain $\sim 1800$ boars producing 3.7 million inseminations per year) and Varkens K1 Twenthe. Only 3\% 'on-farm AI' is used. Boars located on the AI centers originate from several breeding companies such as TOPIGS (94.9\%), PIC (3.4\%), Nord West (0.6\%), Danbred $(0.3 \%)$, JSR $(0.1 \%)$ and others $(0.7 \%)$. In contrast to a lot of other countries, where inseminations are alternated with natural mating within a cycle of a sow, AI is solely used in The Netherlands. The Dutch were the first to introduce the pooling of semen (since 1992) for commercial herds, however since the major outbreak of Classical Swine Fever in 1997, where two pig AI stations were involved as well, the use of pooled semen was prohibited by the Dutch government. Semen production for commercial use in The Netherlands is only allowed on EU approved semen collection centers (Directive 90/429/EEC). All centers of Varkens KI Nederland are under a strict hygienic program, in which critical points in the production are tested on a daily, weekly and monthly schedule for bacteriological contamination. The working methods at the AI stations are standardized and controlled during the whole production procedures $(6,7)$.

Boar ejaculates are collected in separate collection pens on dummy sows using the "gloved-hand" technique (sperm-rich fraction) or in an automated semen collection system (Collectis ${ }^{\circledR}$, IMV technologies). Before semen collection, body temperature is measured to ensure the health status of the boar on the collection day. The semen is transported from the collection area to the lab via a pneumatic tube system. At the AI lab, the semen is extended with a two-step dilution method. The volume of the ejaculate $(\mathrm{ml})$ is diluted with $\sim$ the same volume $(\mathrm{ml})$ of Solusem ${ }^{\circledR}$ short-term $(\leq 72 \mathrm{~h})$ extender at $32^{\circ} \mathrm{C}$ within $15 \mathrm{~min}$ after collection (step 1). After this dilution, semen quality is assessed by measuring sperm motility (fresh, 24 and $72 \mathrm{~h}$ after production) and density using CASA system. Each fourth to sixth ejaculate of a boar is subjectively assessed for sperm longevity and morphological abnormalities (fixed-stained samples) using a phase-contrast microscope. However, when aberrations are observed or when otherwise the ejaculate quality is doubted, each ejaculate of that boar will be evaluated for sperm longevity and morphology. Because morphological evaluations are time-consuming, the results are only available after distribution of semen doses. After semen quality assessment, semen is finally diluted (step 2) with Solusem ${ }^{\circledR} 20^{\circ} \mathrm{C}$ to a minimum of 1.5 billion sperm in $80 \mathrm{ml}$, packaged in tubes via a full automatic filling device and then stored in a temperature-conditioned room at $17^{\circ} \mathrm{C}(6)$.

Extender production is performed on-lab. Therefore, modern water production equipment is available. Water demineralization is performed by reverse osmosis and disinfection is done by UV-lights. The quality of both production water and prepared extender is checked by measuring $\mathrm{pH}$, conductivity, osmolarity and bacteriology. For the transport of insemination doses to the client, temperature-conditioned cars are used. The transport temperature is $17^{\circ} \mathrm{C}$. In The Netherlands almost all pig breeders have temperature controlled boxes or cabinets to store the doses until use on the farm (6).

Varkens KI Nederland records boar- and ejaculate-related data such as boar identification (tattoo \# and name), genetic line and age of the boar ( $25 \pm 12$ months), days between ejaculation (4.5 \pm 2.5 days), AI station, location and date of ejaculate production, semen collector, laboratory where ejaculate is processed, laboratory technician who assessed semen quality, volume and concentration of the ejaculate $\left(84 \pm 11 \times 10^{9}\right.$ sperm per ejaculate), motility (fresh, 24 and $72 \mathrm{~h}$ ), 
morphological abnormalities, concentration of the insemination dose and number of doses produced per ejaculate $\left(35 \pm 15 \times 10^{6}\right)$ in the AI database. At the farms in The Netherlands, the number of inseminations per cycle is 1.6 with a range of 1-3 and $\sim 10-15$ sows are inseminated from semen of one ejaculate (7).

\section{Belgian AI centers}

The size of the herds in the centers varies between 4 and 165 boars, with an average of 45 boars. Semen doses contain at least 3 billion spermatozoa in $100 \mathrm{ml}$ extended semen. Sperm morphology and motility are considered the most important parameters for sperm quality evaluation. Lower limits of $80 \%$ normal spermatozoa and 70\% motility are used. Motility assessment is performed visually in all but one of the AI centers. Ninety-seven percent of AI centers use a short-term semen extender (storage for 3 days). Since semen transport times are short in Belgium, there is no necessity for long-term storage of diluted porcine semen. In $50 \%$ of the AI centers, long-term extenders (storage for 7 days) are used on a part of the collected semen, mainly for storage over the weekend. In some centers, extenders are added to the ejaculate at room temperature, without negative effects on fertility. Belgian porcine AI centers generally incorporate semen quality examinations in their daily routine, especially for motility assessment. In minority of AI centers, especially the smaller ones, semen morphology examination is performed more systematically. This focus on semen quality, together with the consistent use of a sufficient number of spermatozoa per semen dose, reflects the concern of Belgian centers to produce top quality semen doses $(8,9)$.

\section{Pros and cons of AI with liquid-stored and frozen semen}

\section{Liquid semen}

Current procedures of pig AI employ the extension of fresh whole ejaculate gel-free semen with media which guarantee a fertile shelf life between 3-5 days and the use of 2.5-4 billion spermatozoa per insemination in a large volume of liquid-stored semen (70-100 ml) deposited intracervically two or three times during the estrous period. These conditions limit the number of doses that can be prepared from one ejaculate to $\sim 20-25$. To increase the efficient use of spermatozoa of boars of high genetic merits, several strategies have been proposed, including reducing the number of inseminations per estrous period to one insemination only (by increasing the fertile lifespan of sperm cells or improving the prediction of ovulation time) and utilizing new AI techniques, which allow a change in the site of semen deposition such as post-cervical or deep intrauterine insemination $(10,11)$.

At the practical level, semen storage media can be divided into two major groups: those designed for short-term preservation (1-3 days; examples: BTS \& Vital $^{\circledR}$ ) and media for long-term preservation ( $>3$ days; examples: Androhep ${ }^{\circledR}, \quad \mathrm{X}-$ Cell $^{\circledR}$, MULBERRY III ${ }^{\circledR}$, MR-A ${ }^{\circledR}$ and $\operatorname{Acromax}^{\circledR}$ ). The former are mainly used in short distance semen dose distribution networks (such as European systems in which semen doses are frequently produced at the farm itself) while long-term media are generally used in programs such as those in USA and Norway, where the site of semen production is far away from the site of insemination. The advantages of longterm media are: long distance transport, conducting diagnostic tests (PCR and semen evaluation) and improving the organization of tasks at semen collection centers. For a planned semen storage time $<72 \mathrm{~h}$, it is preferable to use a short-term medium as it is less expensive and has been associated with a similar reproductive outcome to that of the long-term one. When semen doses are needed to be stored $>72 \mathrm{~h}$, it is recommended to use a longterm medium on a higher sperm concentration to compensate for reduced sperm viability due to in vitro aging of spermatozoa (12).

One of the most common media is BTS, but many companies commercialize different kinds of media as mentioned above (13). The main limitation of these media is the preservation of semen at $15-18^{\circ} \mathrm{C}$ in special temperature-controlled boxes. This temperature represents a logistic problem not only for the international transportation but also for the on-farm storage. Doubtless, the possibility of preserving semen at a temperature below $15^{\circ} \mathrm{C}$ would help reduce sperm metabolic activity and protect the semen from detrimental effects of microbial contamination. Bacteriospermia is a frequent finding in porcine semen stored in liquid media for 3-7 days before AI (14). Nevertheless, storage of boar semen at $5-8^{\circ} \mathrm{C}$ for $>24$ h decreases the conception and embryo survival rates $(15,16)$. Semen stored at $15-18^{\circ} \mathrm{C}$ has been found more successful based upon farrowing rates and litter size $(12,17)$. 


\section{Frozen semen}

Continued interest in swine frozen semen is based upon its success in the dairy industry. While one bull can produce enough AI doses to serve $\geq 40,000$ cows per year, one boar produces $<40$ doses per week or enough doses to serve $<2000$ sows per year. Furthermore, most cattle receive a single AI with 15 million sperm per dose, while most pigs receive a double insemination of 2.5-3 billion sperm in each of two intracervical AI doses. In swine, the need for a greater number of spermatozoa may be important for achieving high fertilization rates in response to multiple ovulations, the dilute ejaculate, long uterine horns and extended interval from AI to ovulation (18). Frozen semen has an unlimited durability than liquid-stored semen and can be used in breeding sows for the genetic improvement at remote regions. Nonetheless, cryopreservation of boar semen is still expensive, complex and laborious production process. In comparison with liquid semen, the low fertility and prolificacy (2-3 piglets less) after AI with frozen-thawed semen limit its use in the international markets (19). post-thaw dilution of frozen boar semen causes deterioration of sperm quality characteristics (Tables 1-3) (21). In fact, the development of a low-volume deep intrauterine insemination technique has decreased not only the number of frozen sperm needed for successful AI to $\leq 1$ billion but also the detrimental post-thawing 'dilution effect' on spermatozoa (21). This technique coupled with insemination of sows in spontaneous estrus close to the time of ovulation ( $0-4 \mathrm{~h}$ before ovulation; checked by ultrasonography) have improved, to a great extent, the farrowing rate $(81.4 \%)$ and litter size (9.6 piglets) of frozen semen $(10,19,22)$.

Salient features of boar semen and implications for in vitro sperm storage

Spermatozoa, whether present in whole semen or washed suspensions, are comparatively ineffective 'anaerobes'. Unlike those of the human, bull, ram and billy goat, spermatozoa of the boar cannot obtain sufficient energy for powering their motility (total and progressive) from the anaerobic breakdown of fructose or glucose alone. On the contrary, boar spermatozoa are highly effective

Table 1. Influence of extender and post-thawing dilution of frozen boar semen on proportions of sperm progressive motility (21).

\begin{tabular}{llll}
\hline Frozen-thawed & \multicolumn{2}{l}{ Extender } & Overall** \\
\cline { 2 - 3 } semen & Lactose-egg yolk & INRA-egg yolk & \\
\hline Undiluted* & $36.4 \pm 2.0 \mathbf{~ a}$ & $49.5 \pm 1.6 \mathbf{b}$ & $43.0 \pm 1.6 \mathbf{~ a}$ \\
Diluted* & $25.2 \pm 1.9 \mathbf{~ b}$ & $32.7 \pm 2.5 \mathbf{~ a}$ & $29.0 \pm 1.6 \mathbf{b}$ \\
\hline Overall** & $30.8 \pm 1.6 \mathbf{~ a ~}$ & $41.1 \pm 1.9 \mathbf{~ b}$ & $36.0 \pm 1.4$ \\
\hline Means $\left( \pm\right.$ SEM) with dissimilar letters in the same row or column are significantly different $\left(P<0.01^{*}\right.$ and $\left.<0.001^{* *}\right)$
\end{tabular}

Means $\left( \pm\right.$ SEM) with dissimilar letters in the same row or column are significantly different $\left(P<0.01^{*}\right.$ and $\left.<0.001^{* *}\right)$.

Frozen semen is presently used for the international exchange among nucleus farms to help maintain genetic diversity and to reduce the risk of disease transmission associated with boar and liquid semen entry. The use of frozen semen beyond several days can provide increased flexibility for on-farm use and allow additional time for disease tests. There may be a potential use of frozen semen for short-term banking during periods of low demand and while sires await breeding value tests. Opportunities exist for use of frozen semen in long-term banking of sire lines, creation of semen pools for genetic progress evaluation and for use in emergencies (20). The current procedure for AI with frozen semen involves the deposition of a high number of thawed spermatozoa (5-6 billion) extended in $80-100 \mathrm{ml}$ of diluent into the cervix. However, recent findings in our lab show that 'aerobes' and their respiratory coefficient equals that of the bull and ram spermatozoa. The presence of oxygen and sufficient oxidizable energy substrates is essential for maintenance of sperm motility in vitro $(23,24)$. Aerobic incubation of buffered whole semen at $37^{\circ} \mathrm{C}$ for $3 \mathrm{~h}$ causes a complete loss of sperm motility, indicating that boar semen contains insufficient energy substrates and addition of oxidizable substrates is necessary to maintain sperm motility in vitro (23). Boar spermatozoa can metabolize aerobically fructose, glucose, mannose, glycerol, lactic acid, pyruvate, citrate and acetic acid. They are unable to oxidize sorbitol and inositol, presumably owing to absence of the necessary enzyme system. Thus, they differ from ram spermatozoa which readily metabolize sorbitol to fructose using a highly active sorbitol dehydrogenase (23-29). 
Table 2. Influence of extender and post-thawing dilution of frozen boar semen on proportions of live morphologically normal spermatozoa (21).

\begin{tabular}{llll}
\hline Frozen-thawed & Extender & Overall** \\
\cline { 2 - 3 } semen & Lactose-egg yolk & INRA-egg yolk & \\
\hline Undiluted* $^{*}$ & $31.3 \pm 1.6 \mathbf{~ a}$ & $39.1 \pm 2.7 \mathbf{~ b}$ & $35.4 \pm 1.7 \mathbf{~ a}$ \\
Diluted* $^{*}$ & $22.6 \pm 0.6 \mathbf{~ b}$ & $31.0 \pm 1.4 \mathbf{~ a}$ & $26.8 \pm 1.0 \mathbf{~ b}$ \\
\hline Overall** & $26.9 \pm 1.1 \mathbf{~ a ~}$ & $35.2 \pm 1.7 \mathbf{~ b}$ & $31.1 \pm 1.1$ \\
\hline
\end{tabular}

Means $( \pm$ SEM) with dissimilar letters in the same row or column are significantly different $(P<0.01 *$ and $<0.001 * *)$.

The high ratio of unsaturated: saturated fatty acids in the phospholipids and the low cholesterol content of plasma membrane may contribute to the extreme sensitivity of boar sperm to cold shock (2, 30). Therefore, delivering cholesterol to the plasma membrane of boar spermatozoa is associated with increasing their resistance against cold stress (18, 31,32 ), although in a recent study, this treatment does not improve the fertility of frozen semen (33). Spermatozoa of whole ejaculate are more susceptible to cold shock than those of sperm-rich fraction, due to presence of a cold shock sensitizing

\section{Important considerations before implementing AI programs}

The basic requirements for a swine AI program are boar (or semen) selection and purchase, training of boars for semen collection, semen evaluation, processing and storage and estrus detection and insemination. Semen is collected by the "gloved-hand" technique from boars at a frequency of two times per week (43-45). The standard procedure involves collection of the whole ejaculate, a modified whole ejaculate or the sperm-rich fraction (34). Currently, the use of an

Table 3. Influence of extender and post-thawing dilution of frozen boar semen on incidence (\%) of sperm chromatin instability (21).

\begin{tabular}{|c|c|c|c|}
\hline \multirow{2}{*}{$\begin{array}{l}\text { Frozen-thawed } \\
\text { Semen }\end{array}$} & \multicolumn{2}{|l|}{ Extender } & \multirow[t]{2}{*}{ Overall* } \\
\hline & Lactose-egg yolk & INRA-egg yolk & \\
\hline Undiluted** & $3.9 \pm 0.3 \mathbf{a}$ & $1.7 \pm 0.3 \mathbf{b}$ & $2.8 \pm 0.4 \mathbf{a}$ \\
\hline Diluted $^{* *}$ & $6.1 \pm 0.4 \mathbf{b}$ & $3.2 \pm 0.3 \mathbf{a}$ & $4.7 \pm 0.5 \mathbf{b}$ \\
\hline Overall $* * *$ & $5.0 \pm 0.4 \mathbf{a}$ & $2.4 \pm 0.3 \mathrm{~b}$ & $3.7 \pm 0.3$ \\
\hline
\end{tabular}

factor in secretions of boar accessory sex glands $(34,35)$. Incubation of diluted semen above $15^{\circ} \mathrm{C}$ increases sperm resistance to cold shock (36-38). The extreme vulnerability of boar spermatozoa to cold shock means that in practice, semen samples should be kept at $15-20^{\circ} \mathrm{C}$, since a further decrease in the storage temperature below $12^{\circ} \mathrm{C}$ compromises their viability $(39,40)$. Nonetheless, the need to preserve boar semen at these moderately reduced temperatures restricts their storage capacity since cell metabolism cannot be slowed down $(34,41)$ and microbial conditions may not be as effectively controlled as at lower temperatures $\left(5-10^{\circ} \mathrm{C}\right)(42)$. automated semen collection system (Collectis $^{\circledR}$, IMV Technologies) has not only maximized the labor and collection efficiency but also reduced the incidence of bacterial contamination in extended semen. The Collectis ${ }^{\circledR}$ system regulates air pressure and vacuum (similar to those found in the milking palor) to control the volume and pressure of air supplied to an artificial vagina which holds the boar's penis during collection (46).

In view of our experience, the main criteria for selection of a boar stud as a reliable semen supplier are: (a) having a documented quality control program in place, (b) providing a high level of biosecurity in the animal area and the AI laboratory, 
(c) identifying and discarding low quality ejaculates, (d) having well-trained personnel for collection and processing of semen, (e) using high quality water and high quality semen preservation media, (f) using a medium which is appropriate for the duration of semen storage, $(\mathrm{g})$ providing a label on each dose of semen that includes relevant information, such as collection date, sire, identity of semen pool and expiration date, (h) keeping a reference sample of each ejaculate or pool, (i) documenting results of semen evaluation on reference samples, and (j) providing a proper temperature control during shipment of semen doses.

A semen extender is the backbone of the insemination dose. It provides the semen with nutrients and keeps the $\mathrm{pH}$ at the optimum level. The composition of the extender is important for semen longevity (2). Depending on the country, a longer shelf life is important in order to enable long distance transportations (3). In general, costs related to reproduction represent a low proportion of the overall cost of pig production and have been estimated at $1.9 \%$. If we consider that most of this cost is associated with the human resources needed for estrus detection, semen collection and AI, the storage extender represents an insignificant portion of the complete production costs compared with its serious economic consequences on farrowing rates and litter sizes (12). Owing to high personnel costs, most of the labs use powdered preparations or concentrated liquid stock solutions that only require dilution in distilled water (5). This method contrasts with the in-house preparation, which involves separately weighing each component before dilution (6). In most cases, the testicular tissue and accessory glands of the boar are bacteria-free and therefore bacterial contamination of the ejaculate occurs during the semen collection process. An antibiotic should be added to the extender since its components (glucose) and the storage temperature $\left(15-18^{\circ} \mathrm{C}\right)$ promote the growth of gram negative bacteria such as E.coli, Salmonella and Pseudomonas species. Bacterial contamination of stored semen causes diminished sperm motility, sperm agglutination or clumping, damaged sperm acrosomes and reduction of $\mathrm{pH}$ to the acidic levels (5.7-6.4). Thus, adding antibiotics at the appropriate concentration coupled with improving the hygienic measures during semen collection and processing can ameliorate preservability and fertility of semen (14, 42, 47-52). Penicillin plus streptomycin (1 g/L), which still have some importance in suppressing leptospira, were initially the combination most frequently used. Thereafter, aminoglycosides are still successfully used including gentamicin sulfate $(0.2-0.3 \mathrm{~g} / \mathrm{L})$, neomycin sulfate (1 g/L), kanamycin sulfate (0.1-0.2 g/L) and dibekacin (0.1 g/L). Most recently, new generation of antibiotics (ceftiofur and apramycin) are being used, though no conclusive results are available yet $(2,12,53,54)$. Furthermore, since gram negative bacteria are the predominant type detected in boar semen, the endotoxins released after inhibition of these bacteria by the above mentioned antibiotics could bind directly to sperm head region, decrease sperm motility and induce apoptotic-like changes in stored sperm. When combined with penicillin $\mathrm{G}$, polymyxin B $(0.1 \mathrm{mg} / \mathrm{ml}$; a polycationic antibiotic) blocks the negative effects of endotoxins on sperm quality and improves long-term preservability of boar semen (55).

At the legislation level, there are two reference organizations: the Office International des Epizooties (OIE) and the European Union (EU). In its International Animal Health Code (2002), the OIE regulates the criteria to be applied to semen media. This norm recommends that if a medium contains an ingredient such as milk, egg yolk or other animal protein, these should be pathogen-free or sterilized. The addition of antibiotics is permitted, provided they are declared in the corresponding international veterinary certificates. In the EU setting, Directive 90/429/CEE (1990), which regulates health policies applied to the exchange between member states and the import of boar semen, stipulates the use of a combination of antibiotics that should be efficient particularly against leptospirochaetes and mycoplasma. Its concentration should at least have an effect equivalent to the following (per ml): $500 \mathrm{IU}$ penicillin, $500 \mathrm{IU}$ streptomycin, $150 \mathrm{mg}$ lincomycin and $300 \mathrm{mg}$ spectinomycin. Replacement of streptomycin by gentamicin $(0.25 \mathrm{mg} / \mathrm{ml})$ in the latter combination of antibiotics has no negative effect on sperm quality. This norm also indicates that immediately after adding the antibiotics, the diluted semen should be kept at a temperature of at least $15^{\circ} \mathrm{C}$ for a minimum of $45 \min (2,12,56)$.

It is worth noting that there is an increasing move towards supplying semen extenders in a liquid form (rather than as a powder which is dissolved in distilled water immediately prior to use). Since antibiotics have a limited half-life in the liquids, the manufacturers add high concentrations of antibiotics in order to retain a sufficient antibiotic activity over the shelf life of semen extender. This calls the attention towards the potential of development of resistant bacterial strains for these antibiotics. Therefore, any reduction in the use of antibiotics in semen extenders would be desirable $(57,58)$. 
Despite colloidal centrifugation of semen reduces, to some extent, bacterial contamination of boar ejaculates, the harvesting of sperm pellets is performed in a laminar air flow bench, whereas most semen collection stations do not have access to such equipment. This raises the question about the likelihood of re-contaminating the "clean" sperm pellets with bacteria from the environment. Moreover, motile flagellated bacteria are more likely to be present after colloidal centrifugation than non-flagellated bacteria. Under normal conditions, boar semen doses are stored in sealed plastic containers with minimal amount of air. Such anaerobic conditions would also be unfavorable to bacterial growth. It should be noted, however, that neither the purification of semen nor the use of antibiotics is a substitute for good hygienic practices on boar stud farms $(14,57)$.

How to process boar semen for liquid storage in the commercial setting

\section{Principles behind anaerobic storage of semen at $15-20^{\circ} \mathrm{C}$}

In freshly ejaculated boar semen, $\mathrm{pH}$ varies between 7.2 and 7.5, and below this $\mathrm{pH}$ range, sperm motility and metabolism are reduced gradually (2). In sperm cells, the initial production of lactic acid from metabolism of the high glucose content of most semen extenders (e.g. BTS) causes a considerable reduction of intracellular $\mathrm{pH}$ to 6.2 . Since diluted boar semen is placed routinely in plastic tubes with little or no access to oxygen, the accumulation of non-oxidized lactic acid causes intracellular acidosis and subsequent cessation of sperm metabolism and motility. In theory, these conditions enable porcine spermatozoa to survive storage for some days at ambient temperature (23, $25,27,40,59-65)$. Furthermore, maintaining stored boar semen at $\sim 16^{\circ} \mathrm{C}$ will optimize sperm quality characteristics (66).

Incubation of epididymal boar sperm at room temperature for $30 \mathrm{~min}$ with seminal plasma, rather than Ringer-fructose buffer, is associated with low progressive motility and retention of cytoplasmic droplets. This may be due to the presence of insufficient levels of energy substrate in the seminal plasma. However, the initial sperm motility (within $5 \mathrm{~min}$ ) after dilution in the fructose containing buffer is oscillatory (progressive $\&$ total motility $=2-25 \%$ $\& 78-84 \%$ ) and sperm cells acquire their motility on incubation (progressive \& total motility $=64-78 \%$ \& $88-92 \%$ ) for $15-30 \mathrm{~min}$. This has important implications in semen processing: first, dilution of semen should be done with media containing sufficient energy substrates, thus spermatozoa can initiate sperm motility to help shedding off their droplets and then enter a state of cellular anabiosis due to anaerobic conditions of semen preservation. Second, before examination of liquid-stored semen, it is necessary to incubate the samples for at least $30 \mathrm{~min}$ under aerobic conditions at $37^{\circ} \mathrm{C}(23,34,41$, 67-69).

The $\mathrm{pH}$ of semen storage media normally use ranges from 6.8 to 7.2 , but it should be taken into account that in these media, the $\mathrm{pH}$ does not become stable until 60-90 min from the start of dilution with water and that the different extenders show a different pattern of $\mathrm{pH}$ change over time (12). In addition, appropriate measures should be considered when preparing the extender by minimizing its contact with the air and thereby avoiding loss of $\mathrm{CO}_{2}$ from the buffering system of the extender (62), a finding which may explain, in part, the detrimental effects of $\mathrm{pH}$ rise during semen preservation on sperm motility (70).

Boar spermatozoon has an osmotic pressure of $290-300 \mathrm{mOsm} / \mathrm{Kg}$ and can tolerate a relatively wide range of osmotic pressures $(240-380 \mathrm{mOsm} / \mathrm{Kg})$. Neither sperm motility nor viability is affected by osmotic pressures in the range of 250 to $300 \mathrm{mOsm} / \mathrm{Kg}$. However, at osmolarity below $200 \mathrm{mOsm} / \mathrm{Kg}$, sperm motility is significantly reduced (71-73). In the commercial use, isotonic or slightly hypertonic media $(300-330 \mathrm{mOsm} / \mathrm{Kg}$ ) have provided better preservation of sperm fertilizing capacity than hypertonic media (12).

The ideal dilution rate of semen with pure electrolyte media ranges between 1:8 and 1:11 for sperm motility and acrosomal integrity. However, dilution titers of $1: 9$ to $1: 11$ consistently maintain the highest percentage of sperm motility (74). This is of importance during semen preparation for AI: if the calculated dilution titer lies in the normal range ( $\geq 1: 8$ and $\leq 1: 11)$, so extend the semen at the estimated rate; If the calculated dilution titer is below the lower limit $(1: 8)$, it is recommended to dilute the semen at $1: 8$; and If the calculated dilution titer is above the upper limit (1:11), it is recommended to dilute the semen at $1: 11$. The optimum dilution titer differs for each semen medium used for sperm preservation. Initial sperm concentration in the ejaculate and characteristics of the medium, such as initial $\mathrm{pH}$, buffering capacity, and osmotic pressure, can influence the optimum dilution titer during storage (74). Certainly, a 1:10 dilution of sperm-rich fraction of an ejaculate (probably averaging only $60 \times 10^{6}$ sperm $/ \mathrm{ml}$ during 
storage) is not comparable to a 1:10 dilution of the whole ejaculate. Furthermore, the lactic acid concentration in a stored sample of semen will be proportional to sperm concentration. Consequently, a medium with a poor buffering capacity requires a higher dilution rate than a medium with a good buffering capacity (74).

High dilution titers have negative effects on sperm viability and boar seminal plasma protects sperm integrity against this 'dilution effect' (75). Recent observations in our laboratory support this hypothesis (21), where significant effects were detected for the interaction between sperm concentration and presence or absence of boar seminal plasma during semen storage on sperm motility, morphology and chromatin stability (Fig. 1). Under the practical conditions, high dilution rates

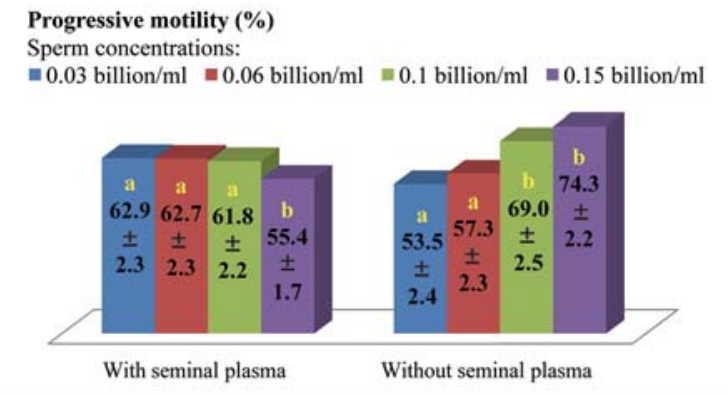

Live morphologically normal sperm (\%) Sperm concentrations:

$=0.03$ billion $/ \mathrm{ml}=0.06$ billion $/ \mathrm{ml}=0.1$ billion $/ \mathrm{ml}=0.15$ billion $/ \mathrm{ml}$

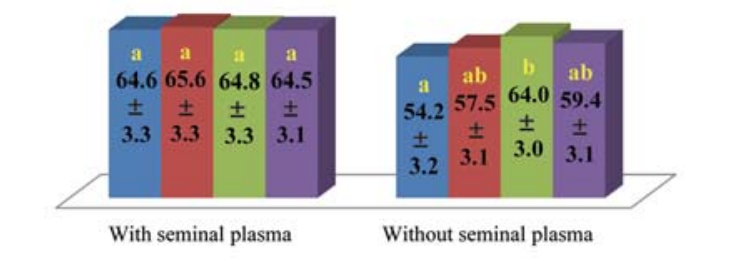

Chromatin instability $(\%)$

Sperm concentrations:

$=0.03$ billion $/ \mathrm{ml}=0.06$ billion $/ \mathrm{ml}=0.1$ billion $/ \mathrm{ml}=0.15$ billion $/ \mathrm{ml}$

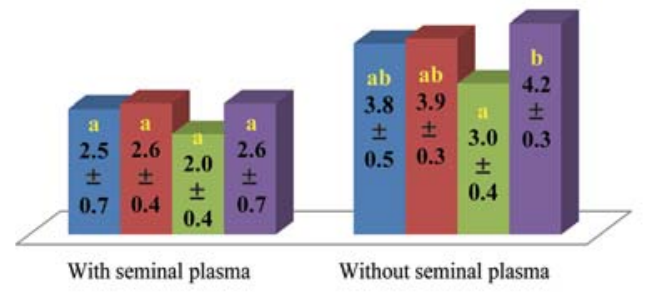

Figure 1. Influence of sperm concentration and presence or absence of seminal plasma during storage of boar semen at $17^{\circ} \mathrm{C}$ for $24 \mathrm{~h}$ in INRA-96 extender (IMV technologies, France) on sperm quality traits (21). Means $( \pm$ SEM) with dissimilar letters within each semen treatment, i.e. with or without seminal plasma, are significantly different at $P<0.05-0.01$. are likely to be a problem than low dilution rates, because keeping the entire inseminate dose in one container is less complex than the initial semen storage at a low dilution titer and then addition of the medium just before AI to provide the optimal inseminate volume $(2,74-76)$.

As boar spermatozoa show a higher percentage of circular movement than those from other species, it is recommended to estimate the different forms of motility, including the progressive motility. Stored semen should be examined daily, with a value of sperm progressive motility above $60 \%$ is considered satisfactory (2). The presence of cytoplasmic droplet (proximal or distal) is a serious morphologic defect, which is of particular importance when semen stored for long-term is used for AI and may be associated with lowered resistance of spermatozoa against in vitro aging (77). The total percentage of cytoplasmic droplets in ejaculates used for AI should not exceed $15 \%$, especially when stored semen is used. The percentage of other morphological alterations should not exceed 20\% $(2,77)$. Strictly, liquid-stored semen used for AI should contain $>60 \%$ progressively motile sperm and $\geq 85 \%$ morphologically normal spermatozoa.

The fertility of liquid-stored boar semen depends mainly on the following factors: initial ejaculate quality and frequency of semen collection, extender type, storage temperature and duration, sperm number per AI dose, insemination volume, number and timing of inseminations relative to ovulation at each estrus as well as the site of semen deposition in the female genital tract $(16,39,45,77-92)$. In addition, a number of factors can also influence the fertility levels in pig farms, including boar breed and age, parity and lactation length, weaning-toestrus interval, season, stress, nutritional status and inseminator skills $(80,85,86,88,91,93-100)$. In the authors' experience, these factors should be taken into account before designing the clinical studies because they may have a confounding influence on the outcome of field-fertility trials. Therefore, the readers are directed to the above stated references for expanding their knowledge regarding the factors which affect the farrowing rate and sow prolificacy after AI with preserved porcine semen.

In the commercial situation, the principal aim of semen storage is to maintain spermatozoa in a viable state for a variable period of time in order to fertilize a high proportion of ova with a minimum sperm dose and at minimal cost and health risk (2). This aim has not been achieved by BTS extender when storage time exceeds 3 days. However, doubling of the 
sperm dosage to 6 billion on the fourth day of storage along with the use of boars with good semen quality can prevent the decline in semen fertility $(2,81)$. Unfortunately, this option is not usually practicable for the commercial use of liquid-stored boar semen. It is our opinion that the higher cost of the long-term extender, such as Androhep ${ }^{\circledR}$ or X-cell ${ }^{\circledR}$, is acceptable because of the higher fertility and prolificacy levels after semen storage for 4-5 days and the possibility of flexible semen handling $(2,77,82,87,90)$.

2. Processing steps for liquid storage of semen using short-term (modified BTS) and long-term (MOPS) extenders in our laboratory (101)

Preparation of modified BTS extender: $3.7 \mathrm{~g}$ D-(+)-glucose anhydrous, $0.6 \mathrm{~g}$ Na-citrate tri-basic $2 \mathrm{H}_{2} \mathrm{O}, 0.125$ g EDTA-2Na, $0.125 \mathrm{~g} \mathrm{NaHCO}, 0.075 \mathrm{~g}$ $\mathrm{KCl}$, sterile-reverse osmosis water up to $106.255 \mathrm{ml}$, $0.5 \mathrm{ml}$ of $5 \%$ gentamicin sulfate solution, and $20 \mu \mathrm{l}$ of citric acid-Hepes solution (0.5245 g citric acid $\mathrm{H}_{2} \mathrm{O}+0.5958 \mathrm{~g}$ Hepes $+2.5 \mathrm{ml}$ water $)$. The medium $(\sim \mathrm{pH} 7.2$ and $310 \mathrm{mOsm} / \mathrm{Kg})$ is then sterilized through a $0.22-\mu \mathrm{m}$ filter.

- Preparation of MOPS extender: $1.2566 \mathrm{~g}$ D-(+)-glucose $\mathrm{H}_{2} \mathrm{O}, 1.733 \mathrm{~g}$ Na-citrate tri-basic $2 \mathrm{H}_{2} \mathrm{O}, 0.2623 \mathrm{~g}$ EDTA-2Na, $0.1319 \mathrm{~g} \mathrm{NaHCO}$, $0.4918 \mathrm{~g}$ Mops, $0.5 \mathrm{~g}$ bovine serum albumin, 0.06 g penicillin $\mathrm{G} \mathrm{Na}$ ( $\geq 1477 \mathrm{U} / \mathrm{mg}), 0.01 \mathrm{~g}$ neomycin sulfate, $0.01 \mathrm{~g}$ kanamycin sulfate and sterile-reverse osmosis water up to $100 \mathrm{ml}$; adjustment of medium $\mathrm{pH}$ (with $1 \mathrm{M}$ solution of citric acid $\mathrm{H}_{2} \mathrm{O}$ ) at 6.7-6.8 and osmolarity at $290-300 \mathrm{mOsm} / \mathrm{Kg}$. The extender is then sterilized through a $0.22-\mu \mathrm{m}$ filter.

- Warm the medium to $37^{\circ} \mathrm{C}$ in a water bath.

- Collect a whole ejaculate in a pre-warmed container using the "gloved-hand" technique.

- Incubate the gel-free semen at $37^{\circ} \mathrm{C}$ and determine ejaculate volume, sperm concentration and progressive motility.

- Calculate the amount of extender required for dilution of the ejaculate based on:

* Semen dilution titers (semen: medium) $=1: 1$ 1:11 (optimum 1:7.5).

* Insemination volume $=80-100 \mathrm{ml}$.

$*$ Insemination dose $=3 \times 10^{9}$ spermatozoa.

* Post-dilution sperm progressive motility $\geq 75 \%$

* Post-dilution morphologically normal sperm $\geq 85 \%$

Add the medium to the semen in a stepwise manner and incubate the diluted ejaculate at $37^{\circ} \mathrm{C}$ for 5-10 $\mathrm{min}$.

- Cool the semen to the required temperature $\left(20-16^{\circ} \mathrm{C}\right)$ at a rate of $-0.10^{\circ} \mathrm{C} / \mathrm{min}$.
- Package the cooled semen. The air-filled spaces above the semen should not be larger than $4.5-10 \%$ of the tube's or bag's capacity.

- Store the insemination doses at $16-20^{\circ} \mathrm{C}$ (optimum $18^{\circ} \mathrm{C}$ ).

- Semen should not be used for AI before $45 \mathrm{~min}$ of the dilution process.

- Semen doses should be rotated at least twice a day during the whole storage period.

- Under the above recommendations, semen fertility and prolificacy can be preserved up to 72 and $120 \mathrm{~h}$ in modified BTS and MOPS extenders, respectively.

How to process boar semen for frozen storage in the commercial setting

1. Theoretical bases behind cryopreservation of boar semen

Boar semen differs in several aspects from that of human and other domestic animals. It is produced in large volumes and is extremely vulnerable to cold shock or sudden cooling immediately after collection (30, 34, 102, 103). Boar spermatozoa are also susceptible to warm shock when cooled semen $\left(5^{\circ} \mathrm{C}\right)$ is rapidly diluted at $25-37^{\circ} \mathrm{C}(104$, 105). Prolonged exposure of spermatozoa to seminal plasma is detrimental to their motility and morphology during cooling and holding of the semen at $5^{\circ} \mathrm{C}$ (Fig. 2) (21). These characteristics require special considerations in the design of freezing protocols for porcine semen.

Successful freezing of boar semen relies on understanding of the factors and their interactions which influence the capacity of spermatozoa to survive freezing and thawing. These factors can be classified into two categories: internal or fixed factors, such as the inherent characteristics of spermatozoa as well as the differences between breeds, boars and ejaculates, and external factors, such as composition of storage media, rates of dilution and cooling, type and concentration of cryoprotective agents, equilibration, and method of freezing and thawing of semen $(2,106)$.

\section{Cooling phase}

Boar spermatozoa acquire a resistance to cold shock simply by incubation at $17-30^{\circ} \mathrm{C}$ for several hours $(36-38,107-111)$. Various factors affect the development of sperm resistance to cold shock. First, seminal plasma of whole ejaculate: acrosomal membranes of epididymal spermatozoa are more resistant to cold shock damage than those of the ejaculated ones $(30,112)$. This is attributed to 


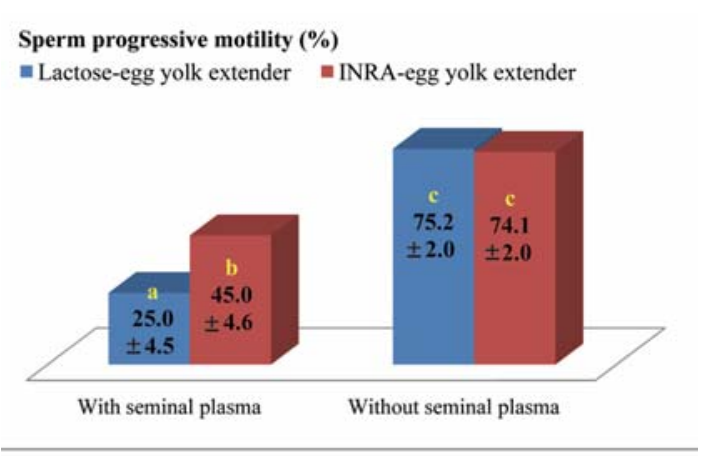

Live morphologically normal sperm (\%)

= Lactose-egg yolk extender $=$ INRA-egg yolk extender

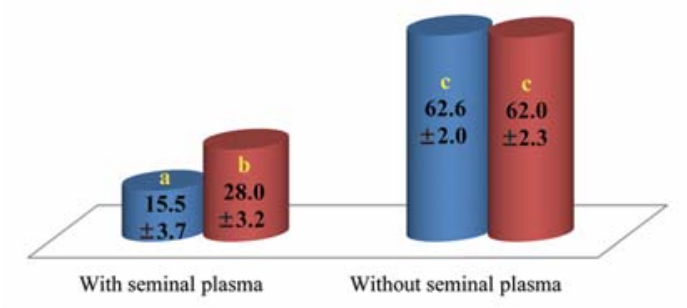

Sperm chromatin instability (\%)

= Lactose-egg yolk extender =INRA-egg yolk extender

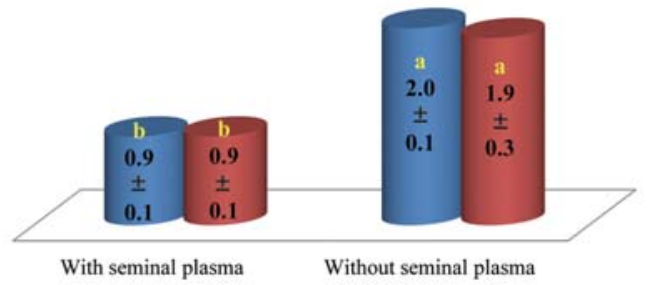

Figure 2. Influence of extender and presence or absence of seminal plasma during storage of boar semen at $5^{\circ} \mathrm{C}$ for $24 \mathrm{~h}$ on sperm quality characteristics (21). Means $( \pm$ SEM) with dissimilar letters are significantly different at $P<0.02-0.0 .001$.

sperm acquisition of a proteinous coat derived from secretions of the seminal vesicle. These proteins are strongly basic, very difficult to dislodge from sperm surface and are capable of increasing permeability of cellular membranes (34). This may explain why sperm-rich fraction, which contains only a low proportion of seminal plasma, develops a more resistance to cold shock than the whole ejaculate (36). Within the sperm-rich fraction, the first $10 \mathrm{ml}$ (P1) are more tolerant to cold stress than the rest of sperm-rich fraction and the post-sperm fraction (P2). Such tolerance is influenced by seminal plasma of the portions because seminal plasma of $\mathrm{P} 1$ increases the resistance of P2-spermatozoa to P1 levels (113).

Second, intrinsic cellular property: washed sperm suspensions have higher percentages of normal acrosome and motility when cold-shocked after 5-h incubation than after 1- or 3-h incubation, indicating that the ability of spermatozoa to develop cold shock resistance during in vitro incubation is an inherent trait within these cells (37). Supporting this hypothesis, when epididymal spermatozoa are extended (1:3) in a Tris-lactose medium and cold-shocked to $0^{\circ} \mathrm{C}$ after 1 - and 5-h incubation, percent sperm with normal acrosome is $4 \%$ and $30 \%$, respectively (37).

Third, incubation period and temperature: increasing the incubation time is associated with increasing sperm resistance against cold shock (progressive motility and acrosomal integrity after 2 and $4.5 \mathrm{~h}$, respectively) (108). Sperm acrosome and motility acquire a more cold shock resistance when cold shock was done after 2.5-, 3- and 5-h incubations than after 0.5 - and 1-h incubations (36, $37,108)$. No studies were conducted regarding the effect of incubation temperature on cold shock resistance of boar sperm. However, maintaining of diluted semen at $\sim 16^{\circ} \mathrm{C}$ overnight improves quality of frozen spermatozoa (66). On the other hand, although extending the holding period of semen from 3 to $24 \mathrm{~h}$ at $15^{\circ} \mathrm{C}$ has no significant influence on freezability and pregnancy rate of frozen spermatozoa, it reduces the potential litter size (114).

Fourth, sperm dilution and seminal plasma of sperm-rich fraction: increasing the dilution rate of sperm-rich fraction from 1:2 to $1: 6$ or $1: 10$ interferes with the development of cold shock resistance by boar sperm during in vitro incubation. Cold shock affects acrosome structure and sperm motility more adversely as the sperm concentration decreases from 278 to $56 \times 10^{6} / \mathrm{ml}$, even though the seminal plasma and spermatozoa make up to $50 \%$ of the final volume of the diluted sample, i.e. at a fixed seminal plasma concentration. It seems that dilution per se increases susceptibility of boar sperm to cold shock because further dilution of 3- and 5-h incubated semen from a rate of 1:2 to rates of 1:6-1:10 decreases sperm motility and acrosomal integrity compared with incubated-diluted semen at a rate of 1:2 (37). However, seminal plasma per se also provides boar sperm with some protection against cold shock damage after 3- and 5-h incubation. It appears that seminal plasma interacts with spermatozoa during incubation to produce the increased resistance to cold shock. In agreement with this opinion, incubation (10 min at room temperature) of cauda epididymal spermatozoa in seminal plasma from intact and vasectomized boars increases their resistance to cold shock by 
$60-80 \%$ (112). Therefore, the detrimental effect of excessive semen dilution on resistance of boar spermatozoa (sperm-rich fraction) to cold shock may stem from a direct adverse effect of dilution on sperm cells, excessive dilution of seminal plasma constituents and a direct interference with incubation-induced development of cold shock resistance. Interestingly, recent studies demonstrate the beneficial effects of low levels of boar seminal plasma on quality and fertility of cooled $\left(5^{\circ} \mathrm{C}\right)$ and frozen-thawed semen (113, 115-120).

Fifth, incubation medium: sperm incubation medium has a significant effect on the development of tolerance to cold stress $(36,121)$. When the spermrich fraction is cold-shocked after 2-h incubation, motility in media with $\mathrm{pH}$ 7.3-8.3 are higher than in those with $\mathrm{pH}$ 5.9-6.6. After 4.5-h incubation in media with $\mathrm{pH}$ range of 5.9-8.3, acrosomal integrity of cold-shocked sperm is higher than that after 1-h incubation. However, sperm acrosomes are more resistant to cold shock after $7-\mathrm{h}$ incubation in media with pH 5.9-7.3 than in media with pH 8-8.3 (108).

Disaccharides (lactose and sucrose) and trisaccharides (raffinose) maintain acrosomal integrity better than monosaccharides (glucose and fructose) after cold shock of 5-h incubated spermatozoa. Fructose maintains acrosomal integrity better than glucose. Sugars do not influence sperm motility after cold shock of incubated semen. Varying levels (0.082-0.246 M) of Tris in the media have no effect on the development of cold shock resistance during semen incubation for 1-5 h (108). Egg yolk (5-30\%) does not protect boar sperm motility and acrosome against cold shock after 1 and 5-h incubation. Sperm acrosomes are more cold shock resistant after 5-h incubation in the absence rather than in the presence of egg yolk. Therefore, egg yolk (20-30\%) interferes with development of cold shock resistance (108). In the absence of seminal plasma of sperm-rich fraction, milk casein

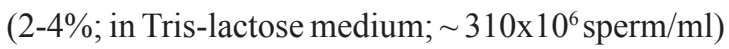
protects sperm acrosome, but not motility, against cold shock damage. However, in the presence of seminal plasma, casein does not provide such protection to sperm acrosome (37).

Boar spermatozoa differ markedly in their response to cold shock compared with bull and ram spermatozoa (2). Chicken egg yolk, lecithin (phosphatidylcholine), cow milk, casein, albumin and globulin have been reported to alleviate cold stress in equine, bovine, ovine and caprine spermatozoa (122-126). On the contrary, whole egg yolk, albumin, globulin, phosphatidylcholine and phosphatidylethanolamine do not protect porcine sperm against cold shock $(37,127)$. Only phosphatidylserine is able to safeguard boar sperm against cold shock (127). Orvus Es Paste (OEP; also known as Equex STM; currently distributed by Nova Chemical, USA and Minitüb, Germany), a synthetic detergent based on sodium and triethanolamine lauryl sulfate, modifies egg yolk constituents and renders egg yolk extenders favorable for low-temperature storage of boar spermatozoa (128-131).

Butylated hydroxytoluene (BHT), a lipophilic chain-breaking antioxidant, has been detected (alone or in combination with egg yolk) to protect spermatozoa from the damaging effects of cooling and warming of boar semen (19, 104, 105, 132-135). However, BHT alone is effective only when spermatozoa are cooled to $5^{\circ} \mathrm{C}$ at a slow rate (133). In our lab, despite we demonstrated that BHT could be an alternative of egg yolk for cooling of goat semen $(136,137)$, we did not observe a similar function for BHT on motility and acrosomal integrity of cooled $\left(5^{\circ} \mathrm{C}\right)$ boar semen (unpublished data), a finding which is in agreement with results of earlier studies on cold-shocked spermatozoa (138, 139). However, a combination of BHT and egg yolk improves boar sperm preservability (135). These observations suggest that it may not be realistic to expect a single compound to stabilize the entire boar sperm plasma membrane during cooling or freezing, but those combinations of lipids and other membrane-stabilizing agents may be required to adequately protect all membrane domains (139).

The low-density lipoprotein (LDL) fraction of avian egg yolk (140-144) and soybean lecithin (145) have also been shown to preserve the structural and functional integrity of cooled $\left(4^{\circ} \mathrm{C}\right)$ and frozen-thawed boar spermatozoa. However, we observed in our lab that soybean lecithin was not as efficient as egg yolk in supporting motility of frozen-thawed boar spermatozoa (unpublished data). Skim milk powder alone or in combination with egg yolk has also been shown to protect boar spermatozoa during cold storage $(130,146)$. Treatment of porcine spermatozoa with cholesterol-loaded cyclodextrins (CLC) increases their tolerance to cold stress during low-temperature processing of semen samples (18, 31-33).

In short, evidences from empirical studies show that skim milk, casein (BF3 extender), BHT in combination with egg yolk, OEP-supplemented egg yolk (TEST and BF5 extenders), phosphatidylserine, 
LDL of egg yolk and CLC can contribute to the protection of boar sperm during the initial cooling $\left(5^{\circ} \mathrm{C}\right)$ phase of semen freezing $(32,127,130$, $131,135,146)$.

\section{Freezing phase}

Many cryoprotective agents have been tested, but none have proved better for preserving boar spermatozoa than glycerol (103). However, porcine sperm cells show a greater sensitivity than those of other domestic animals to glycerol levels adequate for optimum freezing (147). The concentration of glycerol required for maximum survival of spermatozoa is determined by several considerations; one of them is the freezing rate. When static liquid nitrogen vapor and dry ice are used for freezing, the volume and geometry of the semen sample influence the rate of freezing and glycerol concentration used (2). Nevertheless, it is generally accepted that only relatively low concentrations of glycerol may be used to obtain a satisfactory post-thawing sperm survival (128, 131). Glycerolated media are usually added when the partially diluted semen has been cooled to $5^{\circ} \mathrm{C}$. Although the composition of diluents varies, most of them are characterized by low glycerol levels $(2.5-4 \%)$ and a short equilibration period $(2,130)$.

Revisiting the semen-glycerol equilibration time for semen packaged in $0.5-\mathrm{ml}$ straws and protected with various glycerol levels $(0-6 \%)$, indicates that longer times of exposure to $5^{\circ} \mathrm{C}$ are beneficial, with a 4-h equilibration producing the highest value of motile sperm with normal acrosome. As semen with no glycerol benefits from the exposure to $5^{\circ} \mathrm{C}$ similar to glycerolated semen, it seems likely that the holding time at $5^{\circ} \mathrm{C}$ is solely renders spermatozoa less susceptible to the freezing damage (148).

The interaction between glycerol concentration and cooling velocity has been recognized as an inverted U-shape survival curve for boar spermatozoa frozen over a range of cooling rates from $1^{\circ} \mathrm{C}$ to $1500^{\circ} \mathrm{C} / \mathrm{min}(147,149)$. The optimum cooling rate shifts to higher values with the decreasing glycerol concentration. It is also shown that the optimum glycerol concentration varies with the parameter investigated: for sperm motility, the best glycerol concentrations are 3-4\% whereas for acrosomal integrity, the optimum concentration is $0-1 \%$. This is attributed to the complicated structure of the spermatozoon which comprises several geometries and different regions. The optimum conditions for one part of the cell may be unsuitable for other regions, or the damage to some parts may have greater consequences than to the others (103). Thus, for preservation of both sperm traits, it is recommended a compromise with $3 \%$ glycerol and freezing rate of $30^{\circ} \mathrm{C} / \mathrm{min}$ (149). It is worth noting that the gradual decrease in motility and acrosome integrity of boar sperm cells as the glycerol concentration exceeds $6 \%$ may be due to the chemical toxicity of glycerol, or to the osmotic shock by rapid dilution of the glycerol at thawing (103,105).

\section{Warming phase}

The rate of thawing of frozen semen through the critical temperature range is an important factor affecting survival of spermatozoa (150). In boar semen frozen at the optimum rate (e.g. $30^{\circ} \mathrm{C} / \mathrm{min}$ ) in $0.5-\mathrm{ml}$ straws (149), sperm motility and acrosome integrity are improved with increasing the thawing rate. This is consistent with the well known 'two-factor' hypothesis that cryoinjury after rapid freezing is caused predominantly by the re-growth of minute ice crystals during slow thawing and that a high warming velocity is essential for sperm cryosurvival $(151,152)$, although no convincing evidence of intracellular ice formation has ever been obtained for sperm cells (150). In fact, recent evidence shows that sperm damage at rapid rates of cooling is a result of an osmotic imbalance encountered during thawing, not intracellular ice formation (150). Three findings may support this evidence: (a) the effect of thawing rate on the acrosome integrity is influenced by the osmotic stress induced by the glycerol concentration, higher concentrations being more damaging to acrosomal integrity (147), (b) rapid warming of cooled-glycerolized (1\%) boar semen to $37^{\circ} \mathrm{C}$ causes a significant damage in sperm acrosome, which can be minimized by pre-treatment of spermatozoa with the antioxidant, BHT (105), and (c) post-thaw dilution of frozen boar sperm causes a significant reduction in their quality traits (Tables 1-3) (21), probably due to a hyperosmotic stress imposed by rapid removal of glycerol from thawed spermatozoa $(113,153)$ and/or an oxidative stress caused by removal of seminal plasma constituents during semen processing (75). Indeed, recent studies demonstrate that exposure of sperm cells to anisosmotic stress stimulates production of reactive oxygen species (154) and post-thaw supplementation of frozen boar semen with seminal plasma improves sperm quality and fertility $(115,120)$. 
In brief, according to the procedures developed quasiempirically over the past decades, effective freezing of boar sperm requires the optimum combination of three main variables: glycerol concentration, cooling and warming velocities. Considering the maintenance of sperm motility and acrosome integrity, the optimum represents a compromise: $3 \%$ glycerol, a freezing rate (in the range between $0^{\circ} \mathrm{C}$ and $-50^{\circ} \mathrm{C}$ ) of $30^{\circ} \mathrm{C} / \mathrm{min}$ and a thawing rate of $1200^{\circ} \mathrm{C} / \mathrm{min}(2)$.

2. Processing steps for frozen storage of semen in our laboratory (21)

- Preparation of semen processing media:

* Warm the holding medium to $37^{\circ} \mathrm{C}$. The medium is composed of $1.9636 \mathrm{~g}$ Tris, $0.9567 \mathrm{~g}$ citric acid anhydrous, $4.9154 \mathrm{~g} \alpha$-lactose $\mathrm{H}_{2} \mathrm{O}$, $0.2960 \mathrm{~g} \mathrm{D}$-(-)-fructose, $0.0395 \mathrm{~g} \mathrm{KCl}, 0.0991 \mathrm{~g}$ EDTA-2Na, $0.01 \mathrm{~g}$ kanamycin sulfate and sterile-reverse osmosis water up to $100 \mathrm{ml}$. The medium ( $\mathrm{pH}$ 7.3-7.4 and $330 \mathrm{mOsm} / \mathrm{Kg}$ ) is then sterilized through a $0.22-\mu \mathrm{m}$ filter.

* Cool the cooling medium to $18^{\circ} \mathrm{C}$. The medium consists of $7.5 \mathrm{ml}$ chicken egg yolk, $92.5 \mathrm{ml}$ INRA-96 extender and 0.1 g EDTA-2Na. INRA-96 is a ready-to-use sterile extender ( $\mathrm{pH} 6.9 ; 307 \mathrm{mOsm} / \mathrm{Kg}$ ) containing a solution of Hank's salts, glucose and lactose, buffered by Hepes and supplemented with native phosphocaseinate $(27 \mathrm{~g} / \mathrm{L})$, penicillin $(50 \mathrm{IU} / \mathrm{ml})$, gentamicin $(50 \mu \mathrm{g} / \mathrm{ml})$ and amphotericin B $(0.25 \mu \mathrm{g} / \mathrm{ml})$ (IMV technologies).

* Cool the freezing medium to $5^{\circ} \mathrm{C}$. The medium consists of $7.5 \mathrm{ml}$ chicken egg yolk, $9 \mathrm{ml}$ glycerol (> 99\%), $83.5 \mathrm{ml}$ INRA-96 extender and $0.1 \mathrm{~g}$ EDTA-2Na.

- Semen collection:

* Collect good quality samples (sperm-rich fractions) in a pre-warmed container from boars with known sperm freezability 'good freezers'.

* Incubate the semen at $37^{\circ} \mathrm{C}$ and determine semen volume, sperm progressive motility and concentration using a pre-calibrated photometer.

- Primary holding and cooling (development of sperm resistance to cold shock):

* Extend the semen with the holding medium at a dilution titre (semen: medium) of 1:1 to $1: 2$.

* Cool the semen from $37^{\circ} \mathrm{C}$ to $18^{\circ} \mathrm{C}$ at a rate of $0.10^{\circ} \mathrm{C} / \min (\sim 3.2 \mathrm{~h})$.

* Estimate sperm cell concentration using a Neubauer hemocytometer chamber.
- Centrifuge the semen at $2400 \times \mathrm{g}$ for $3 \mathrm{~min}$ $\left(18^{\circ} \mathrm{C}\right)$ for removal of seminal plasma and concentrating of spermatozoa.

- Secondary cooling (cooling of spermatozoa to $\left.5^{\circ} \mathrm{C}\right)$ :

* After centrifugation and removal of seminal plasma, re-suspend sperm pellet in the cooling medium at $18^{\circ} \mathrm{C}$ to a concentration of $1.5 \times 10^{9} \mathrm{sperm} / \mathrm{ml}$.

* Cool the semen from $18^{\circ} \mathrm{C}$ to $15^{\circ} \mathrm{C}$ at a rate of $-0.1^{\circ} \mathrm{C} / \mathrm{min}$ and then from $15^{\circ} \mathrm{C}$ to $5^{\circ} \mathrm{C}$ at a rate of $-0.067^{\circ} \mathrm{C} / \mathrm{min}(\sim 3 \mathrm{~h})$.

- Secondary holding, glycerolization and equilibration (development of sperm resistance to freezing damage):

* After cooling, hold the semen at $5^{\circ} \mathrm{C}$ for $1 \mathrm{~h}$.

* Add the freezing medium to the cooled semen at a ratio of 1 part of the medium to 2 parts of cooled semen to achieve concentrations of $1.0 \times 10^{9} \mathrm{sperm} / \mathrm{ml}$ and $3 \%$ glycerol. The addition of freezing medium should be done over a 20 -min period in 4 fractions at 5-min intervals.

* Equilibrate the glycerolized semen at $5^{\circ} \mathrm{C}$ for $1 \mathrm{~h}$ before freezing.

- Packaging of equilibrated semen:

* Fill 0.50-ml straws pre-cooled to $5^{\circ} \mathrm{C}$ with semen (400-450 $\mu \mathrm{l} /$ straw).

* Seal the straws and place them horizontally onto pre-cooled $\left(5^{\circ} \mathrm{C}\right)$ freezing racks.

- Two methods are recommended for freezing of semen:

* Horizontal exposure of straws to static liquid nitrogen $\left(\mathrm{LN}_{2}\right)$ vapor: maintain the straws for $20 \mathrm{~min}$ at $3 \mathrm{~cm}$ above the level of $\mathrm{LN}_{2}$ and then plunge them into $\mathrm{LN}_{2}$.

* Controlled-rate freezing: transfer the straws horizontally in the racks to a programmable freezer pre-cooled to $5^{\circ} \mathrm{C}$. Freeze the straws using one of the following freezing curves:

(a) From +5 to $-4.5^{\circ} \mathrm{C}$ at $-1{ }^{\circ} \mathrm{C} / \mathrm{min}, 60 \mathrm{~s}$ at $-4.5^{\circ} \mathrm{C}$, from $-4.5^{\circ} \mathrm{C}$ to $-180^{\circ} \mathrm{C}$ at $-30^{\circ} \mathrm{C} / \mathrm{min}$ and then plunge the straws into $\mathrm{LN}_{2}$.

(b) From +5 to $-5^{\circ} \mathrm{C}$ at $-6^{\circ} \mathrm{C} / \mathrm{min}$, from $-5^{\circ} \mathrm{C}$ to $80^{\circ} \mathrm{C}$ at $-40^{\circ} \mathrm{C} / \mathrm{min}, 30 \mathrm{~s}$ at $-80^{\circ} \mathrm{C}$, from $-80^{\circ} \mathrm{C}$ to $-150^{\circ} \mathrm{C}$ at $-70^{\circ} \mathrm{C} / \mathrm{min}$ and then plunge the straws into $\mathrm{LN}_{2}$.

- Thawing of frozen semen:

* Warm the modified BTS extender to $37^{\circ} \mathrm{C}$.

* Individually immerse the frozen straws in a circulating water bath at $50^{\circ} \mathrm{C}$ for $20 \mathrm{~s}$.

* Incubate the frozen-thawed semen at $37^{\circ} \mathrm{C}$ for 5-10 $\mathrm{min}$. 
* Extended the semen to $0.05-0.3 \times 10^{9} \mathrm{sperm} / \mathrm{ml}$ with BTS. In order to minimize the osmotic stress on spermatozoa, post-thaw dilution of frozen semen should be done gradually over a 20 -min period in 4 fractions at 5 -min intervals.

\section{How to improve fertility and prolificacy of boar semen after $\mathrm{AI}$}

\section{Colloidal purification of porcine semen}

\section{Concepts behind isopycnic purification of semen samples}

In AI programs, some boars of high genetic value may have ejaculates of low quality traits and poor preservability. These ejaculates are always discarded before or after semen processing leading to economic losses in view of decreasing availability of insemination doses from genetically superior sires. The presence of abnormal or dead sperm, bacteria and leukocytes in semen samples has been suggested to have a detrimental effect on the fertilizing potential of AI doses (14, 42, 48-51, 155, 156).

Similarly, the occurrence of bacterial endotoxins and mycotoxins in boar ejaculates may be responsible for a rapid deterioration in sperm quality traits during liquid storage of semen $(55,157-162)$. In addition, studies on hygienic aspects of semen storage for AI indicate that supplementation of extenders with antibiotics is not enough to eliminate the detrimental influence of bacteria on sperm motility, viability and fertility $(52,163,164)$. There is also a potential risk of transmitting pathogenic microorganisms through AI with stored semen (47, 52, 163-165).

Consequently, purification of porcine semen aims at: (a) improving quality and storageability of AI doses by selecting spermatozoa with competent structural and functional integrity as well as by reducing the concentration of bacteria and toxins which may contaminate boar ejaculates (55, 158,166-169), (b) raising the biosecurity standard of AI programs by removing the potential pathogenic bacteria and viruses from semen doses $(57,58,164,170)$, and (c) teleologically, minimizing development of antibiotic-resistant strains of bacteria through decreasing the use of antibiotics in storage extenders $(57,164)$.

Ejaculated spermatozoa are characterized by a pronounced heterogeneity in morphology, motility, viability and genomic integrity (172). When semen samples are centrifuged through a column of colloidal silica particles, cells move to a point that matches their own density-the isopycnic point, and by altering the centrifugation force and time along with the physical properties of the colloid, the good quality spermatozoa are allowed to pellet in the bottom of the tube $(58,173-177)$. Several intrinsic properties of colloidal silica make it ideal for preparing density gradients for selecting sperm cells. First, as a mineral substance, it has no osmotic effects when added to the culture medium; second, it allows high-density (high specific gravity) media to be prepared, which is important because normal,
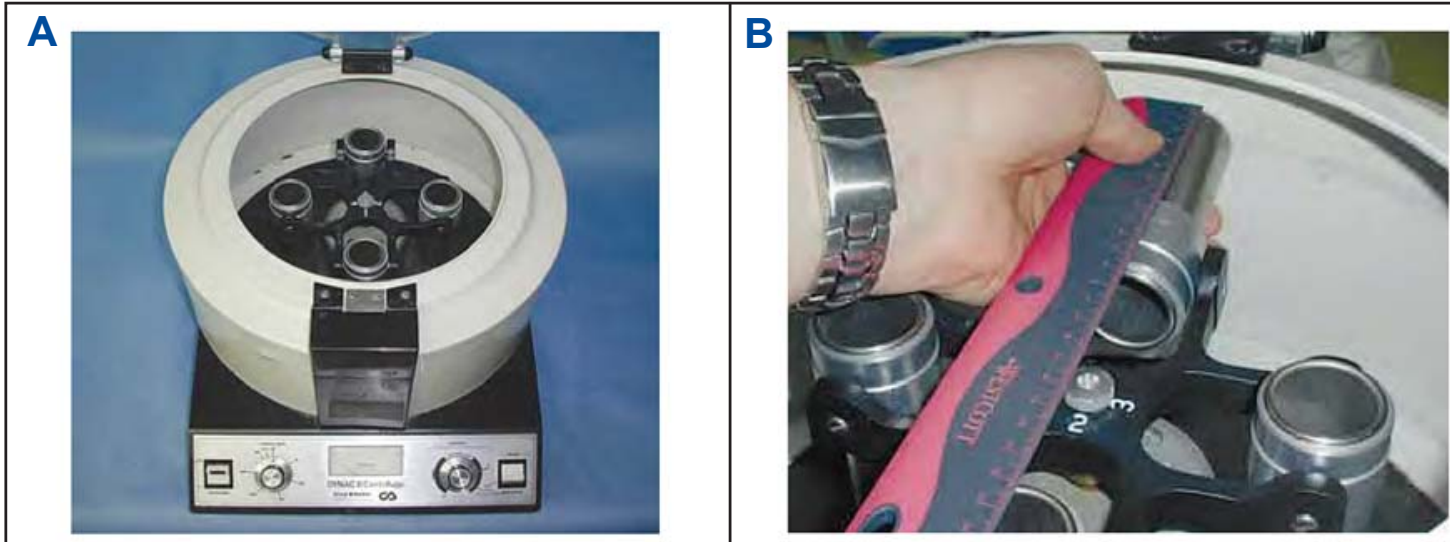

Figure 3. (A) Table-top centrifuge with a swinging-bucket rotor that accommodates 50-ml centrifuge tubes and can generate a relative centrifugal force of 300-1000 times gravity. (B) Determining the rotating radius of a centrifuge by measuring the distance from the center of the rotor to the bottom of a bucket in "swinging" position. In the centrifuge shown in the image, the rotating radius is $17 \mathrm{~cm}$. The length of the rotating radius is plotted against the revolutions per minute (RPM) on a relative centrifugal force nomograph chart to determine the force times gravity (g-force) as shown in Fig. 4; adapted from Vanderwall (178). 
mature mammalian spermatozoa are dense cells; and third being a colloid rather than a solution, it has a low viscosity, and thus it does not retard sedimentation of sperm cells (174). Some 20 years ago, silane-coated silica colloid became available that could be sterilized by autoclaving and it had a low level of endotoxins (58). Silane-coated silica colloid has the advantage of being stable for long periods in salt solutions, and hence permitting standardized formulations to be sold commercially (58). Two products of ready-to-use silane-coated silica colloid are currently marketed for boar semen, namely PociPure ${ }^{\mathrm{TM}}$ (Nidacon International, Mölndal, Sweden) and Androcoll ${ }^{\mathrm{TM}}$-P (Swedish University for Agricultural Sciences, Uppsala, Sweden) $(57,167,170)$.

Procedures used in our lab for single layer centrifugation of semen over PociPure ${ }^{T M}$

- Equipments and media required:

* Table-top centrifuge with a swinging-bucket rotor (Fig. 3).

* Disposable sterile plastic conical bottom 50-ml centrifuge tubes.

* Disposable sterile "serologic" pipettes (5 and $10 \mathrm{ml}$ ) equipped with a manual pipettor (e.g. bulb or thumb-wheel style) for aspirating supernatant fluid.

* Prepare and warm the modified BTS (antibioticfree) medium to $37^{\circ} \mathrm{C}$.

* Prepare and incubate the MOPS extender at room temperature $\left(\mathrm{RT}, 22^{\circ} \mathrm{C}\right)$. The concentration of antibiotics in the extender can be decreased to $20 \%$ of its original concentrations described above. Also, incubate PociPure ${ }^{\mathrm{TM}}$ colloid at RT.

- Semen collection and evaluation:

* Collect gel-free whole ejaculates or spermrich fractions in a pre-warmed container using the 'gloved hand' technique and incubate the semen at $37^{\circ} \mathrm{C}$.

* Determine semen volume and sperm concentration, e.g. whole ejaculate: $200 \mathrm{ml}$ \& $0.2 \times 10^{9} \mathrm{sperm} / \mathrm{ml}$; sperm-rich fraction: $25-50 \mathrm{ml} \& \geq 0.8-1 \times 10^{9} \mathrm{sperm} / \mathrm{ml}$.

- Semen dilution:

* Extend the entire semen sample with isothermic BTS to $0.1 \times 10^{9}$ sperm $/ \mathrm{ml}$.

* Incubate the diluted semen at RT for $15 \mathrm{~min}$.

- Centrifugation of diluted semen:

* Determine the centrifugation speed using a nomograph chart or a formula (Fig. 4).

* Transfer $20 \mathrm{ml}$ of PorciPure colloid to a centrifuge tube.
* Layer $20 \mathrm{ml}$ of diluted semen on the top of the colloid column, resulting in a total volume of $40 \mathrm{ml}$ (semen to colloid ratio $=1: 1$ ).

* Centrifuge the semen/colloid column at $300 \mathrm{x} \mathrm{g}$ for $20 \mathrm{~min}$ at RT.

* Aspirate the supernatant and re-suspend sperm pellet in an initial volume of MOPS extender at RT. Examine sperm motility and determine sperm concentration.

* Process the purified sperm suspension (Fig. 5) for liquid storage as described above.

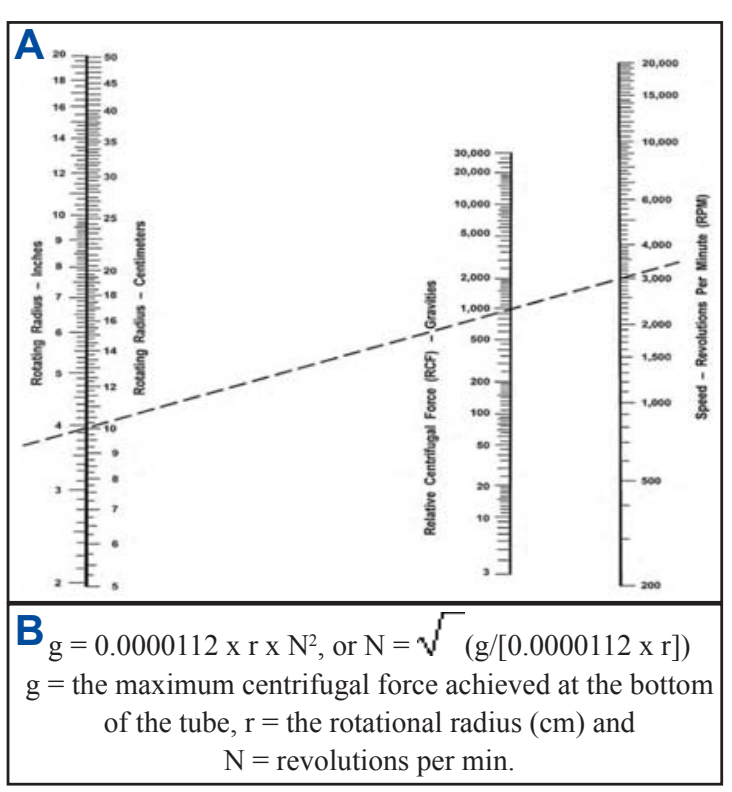

Figure 4. (A) Relative centrifugal force (RCF) nomograph chart for calculating the force times gravity (g-force) from a known rotating radius and revolutions per minute (RPM). To determine the g-force, place a straightedge on the nomograph chart connecting the known RPM and known rotating radius (in inches or centimeters) of the centrifuge. The point at which the straightedge intersects the RCF axis is the g-force. The dashed line represents an example of an RPM of 3000 and rotating radius of $10 \mathrm{~cm}$ that produces a $\mathrm{g}$-force of 1000 ; adapted from Vanderwall (178). (B) A formula describes the relationship between rotation speed, rotational radius and centrifugal force (174).

\section{Modulation of the uterine defense mechanism}

\section{Theoretical background}

After AI, the number of spermatozoa in the female genital tract of the sow decreases to $5-10 \%$ within a few hours. Up to $50 \%$ of the spermatozoa are lost due to the back flow of semen in the first few hours after AI. Another important cause of 
the rapid decrease of the number of spermatozoa in the genital tract is phagocytosis of spermatozoa by polymorphonuclear neutrophils (PMNs). These cells migrate into the uterine lumen directly after $\mathrm{AI}$ and within $2 \mathrm{~h}$ their number reaches the same as the number of spermatozoa. Teleologically, PMNs recruitment and phagocytosis of spermatozoa can be considered as a normal physiological response to clean the genital tract in preparation for reception of the embryos. Phagocytosis of spermatozoa has also been suggested as a mechanism for preferential elimination of senescent or dead spermatozoa, or spermatozoa with a decreased fertilizing potential (179, 180).

On the other hand, treatment of boar semen to induce capacitation in vitro substantially reduces sperm phagocytosis (179). The uterine environment in vivo also provides conditions for capacitation. Spermatozoa can be fully capacitated in the uterus without ascending to the oviducts. Therefore, the reduction in phagocytosis observed after treatment to induce capacitation in vitro may also occur in vivo in the uterus. Spermatozoa may acquire a protection against phagocytosis while in the uterus, which may increase their chance to reach the isthmus and participate in the fertilization (179). In agreement with the above hypothesis, a recent investigation

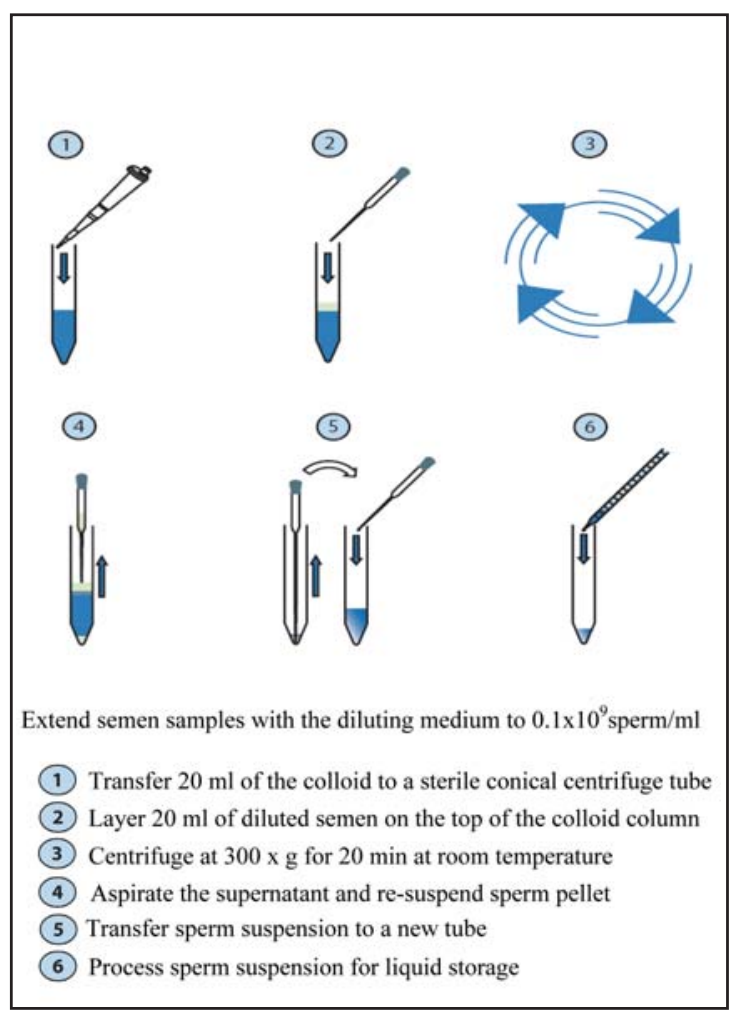

Figure 5. A protocol of porcine sperm selection (PorciPure $^{\mathrm{TM}}$-Nidacon) demonstrates that litter size increases in proportion to the number of capacitated sperm (assessed by chlortetracycline assay) in liquid-stored boar semen (181).

Caffeine, a member of the methylxanthine family, has been found to increase concentrations of intracellular cyclic adenosine monophosphate (cAMP) by inhibition of cAMP-phosphodiesterase in spermatozoa and immune cells $(34,182,183)$. As a consequence, in vitro addition of caffeine to boar semen stimulates sperm capacitation and kinematic activity, along with shedding of cytoplasmic droplets from sperm cells $(69,184-186)$. Moreover, it is believed that caffeine has a potent immunomodulatory effect as evidenced by its ability to decrease the chemotactic and phagocytic activities of blood PMNs when co-incubated in vitro with boar spermatozoa $(187,188)$.

In vivo, Matthijs et al. (180) suggests the following scenario after AI with liquid-stored boar semen: shortly after insemination, spermatozoa are still bathed in the BTS extender containing EDTA, which effectively blocks phagocytosis and capacitation as well. Most of the liquid flows back and is voided through the vulva, and about $35-45 \%$ of sperm are lost with it. Spermatozoa that are not lost with the backflow apparently have made the passage to the endometrial mucus and are thus retained. This new environment presents the conditions that allow phagocytosis, resulting in phagocytosis and digestion of large numbers of spermatozoa. In addition, these conditions allow the onset of capacitation rendering spermatozoa less vulnerable to phagocytes. Supplementation of BTS medium with caffeine and $\mathrm{CaCl}_{2}$ advances or accelerates these processes and reduces the recruitment of PMNs to the uterine lumen, leading to increasing the number of spermatozoa colonizing the oviducts, and thereby improving the probability of fertilization to occur.

Besides the above stated scenario, the procedures of porcine semen storage which involve dilution and/or removal of seminal plasma constituents, as well as the use of BTS extender and egg yolk, can exaggerate the inflammatory response of the endometrium after $\mathrm{AI}$, resulting in increasing of the chemotactic and phagocytic activities of uterine PMNs (188-190). Actually, caffeine alleviates this post-insemination inflammatory reactivity, increases numbers of spermatozoa colonizing the female genital tract, and in turn improves the pregnancy and farrowing rates of gilts and sows (186, 191-193). 
Procedures of caffeination of semen doses in our lab

- Preparation of the caffeination medium: $0.5652 \mathrm{~g}$ Tris, $3.0243 \mathrm{~g}$ D-(-)-fructose, $0.69 \mathrm{~g}$ Na-citrate tri-basic $2 \mathrm{H}_{2} \mathrm{O}, 0.24 \mathrm{~g} \mathrm{NaHCO}, 2.5 \mathrm{~g}$ caffeine, $0.01 \mathrm{~g} \mathrm{CaCl}_{2} .2 \mathrm{H}_{2} \mathrm{O}$ and sterile-reverse osmosis water up to $100 \mathrm{ml}$; adjustment of medium $\mathrm{pH}$ (with $1 \mathrm{~N} \mathrm{HCl}$ ) at 7.4-7.5. The medium is then sterilized through a $0.22-\mu \mathrm{m}$ filter.

Characteristics of the medium:

It is a concentrated sterile solution that, if added to liquid-stored or frozen-thawed semen just before insemination, it increases the pregnancy and farrowing rates by $\sim 15-20$ points. It can be used to maximize fertility of semen in the following cases:

* AI with reduced sperm dose (1.5-2 x109 sperm), which allows maximum utilization of semen from genetically superior sires.

* AI of sows which come early or late in post-weaning estrus.

* AI with semen having suboptimal quality spermatozoa such as frozen-thawed semen, sex-sorted semen and liquid semen that has been stored in a short-term extender $>2$ days or in a long-term medium $>4-5$ days.

* AI with semen obtained from young $(<1$ years old) and aged ( $>5$ years old) boars.

* AI with liquid-stored semen during the summer season.

* AI of superovulated sows in the embryo transfer programs.

- Application of the medium:

* Warm up the medium to $37^{\circ} \mathrm{C}$ and transfer the required amount to the insemination bottle by a sterile 1- or 2-ml syringe. Shake gently the bottle to ensure complete mixing of the semen with the medium and then inseminate. To achieve optimum results, treated semen should be used within 1-15 min after addition of the medium

* The medium should be added to liquid-stored or frozen-thawed semen at a rate of $10 \mu \mathrm{l}$ medium to $1 \mathrm{ml}$ diluted semen. Examples are given in the following table:
3. Site of semen deposition in the reproductive tract during AI

\section{Intracervical AI}

\section{Liquid-stored semen}

The insemination procedure of standard cervical AI deposits the semen dose within the posterior portion of the cervical canal $(\sim 15 \mathrm{~cm}$ deep into the cervix) by means of a catheter that engages the folds of the cervix (Fig. 6). In order to achieve systematic high fertility rates among pig farms, the protocol recommends deposition of $3 \times 10^{9}$ spermatozoa in a large volume $(80-100 \mathrm{ml})$, two or three times during the estrus period (194). It is worth noting that while unsatisfactory results have resulted when AI dose is reduced below $2.5 \times 10^{9}$ spermatozoa, wellmanaged herds achieve high fertility rates with only $2 \times 10^{9}$ spermatozoa per insemination. Moreover, even $1 \times 10^{9}$ spermatozoa per dose can give good fertility provided that the timing of AI is optimal and no backflow of semen during insemination occurs (194). The optimal time for AI is in the interval from $28 \mathrm{~h}$ before to $4 \mathrm{~h}$ after ovulation. However, the highest fertility can be seen when liquid-stored semen is placed in the reproductive tract within 12-24 $\mathrm{h}$ before ovulation, regardless of sperm number delivered (11). Fixed-time AI (single or double) is not usual when liquid semen is used. Currently, sows are bred every $24 \mathrm{~h}$ from the start of the estrus until the standing reflex is no longer detected, resulting in $>2.5$ average number of inseminations per estrus (11).

\section{Cryopreserved semen}

During the last decade, optimal fertility results with frozen semen have been reported if sows or gilts are inseminated intracervicallly 2-3 times in the natural or induced estrus with $5-6 \times 10^{9}$ spermatozoa per AI dose ( $\sim 2-3 \times 10^{9}$ motile sperm per dose) (11, 199). The biological reason of this large number of sperm per AI dose may be related to weakness of frozen-thawed spermatozoa, which are especially vulnerable to loss of their functional competence during the transit through the long reproductive tract of the female pig (11). In USA, a feasibility study for freezing cost per ejaculate is estimated at $\$ 275$ per ejaculate or \$11 per dose of frozen-thawed

\begin{tabular}{c|c|c|c|c|c|c|c|c|c|c|c}
\hline Medium (ml) & 1 & 0.9 & 0.8 & 0.7 & 0.6 & 0.5 & 0.4 & 0.3 & 0.2 & 0.1 & 0.05 \\
\hline Semen dose $(\mathrm{ml})$ & 100 & 90 & 80 & 70 & 60 & 50 & 40 & 30 & 20 & 10 & 5 \\
\hline
\end{tabular}


semen at standard doses of $5 \times 10^{9}$ total frozen sperm. This cost estimate does not include genetic value, fixed equipment costs, depreciation, or variable lab space fees (199).

\section{Transcervical AI}

Despite the high number of sperm delivered via cervical AI, most of them do not participate in the fertilization process because they are rapidly evacuated from the reproductive tract by backflow during or immediately after AI (30-40\% of the total number of spermatozoa deposited into the cervical canal), trapped and die in the cervical folds (5-10\%) and phagocytosed in the uterus (up to $60 \%$ ) (11). Therefore, several different instruments have been developed to transverse the cervix and deposit the semen either in the uterine body "posterior horn" (intrauterine insemination; IUI) $(89,195)$ or in the uterine horn (deep intrauterine insemination; DIUI) (196, 197).

Nevertheless, careful attention should be paid to proper transcervial AI technology to minimize the incidence of cervical and uterine damage which negatively influences the reproductive longevity of sows and gilts in the farm $(194,198)$.

\section{IUI with liquid-stored semen}

The main obstacle to the trans-cervical AI is the presence of folds in the cervical canal (194). In our laboratory, we use a deep insemination device, called the Deepglodenpig ${ }^{\mathrm{TM}}$ catheter (IMV technologies). It involves a standard catheter through which a narrow soft inner tube ( $4 \mathrm{~mm}$ outer diameter) passes and extends $200 \mathrm{~mm}$ beyond the tip of the outer catheter and penetrates the cervical canal to lie in the body of the uterus or the posterior horn (Fig. 6-8). The tip of the deep inseminating device carries a smooth rounded white plastic plug with side holes to permit the passage of diluted semen (Fig. 6). On withdrawal, the white tip enables the immediate identification of any blood. The procedures of IUI with liquid-stored semen are shown in Fig. 9. More than $95 \%$ of the sows can be easily inseminated with this device and if some resistance is felt during introduction of the catheter, it is necessary to withdraw and reposition of the catheter. On average, the whole insemination procedure takes no more than $5 \mathrm{~min}$, and the placing of the device takes no more than a minute. Although IUI with liquidstored semen is currently used by practitioners in the EU and USA, sperm numbers per AI dose is not

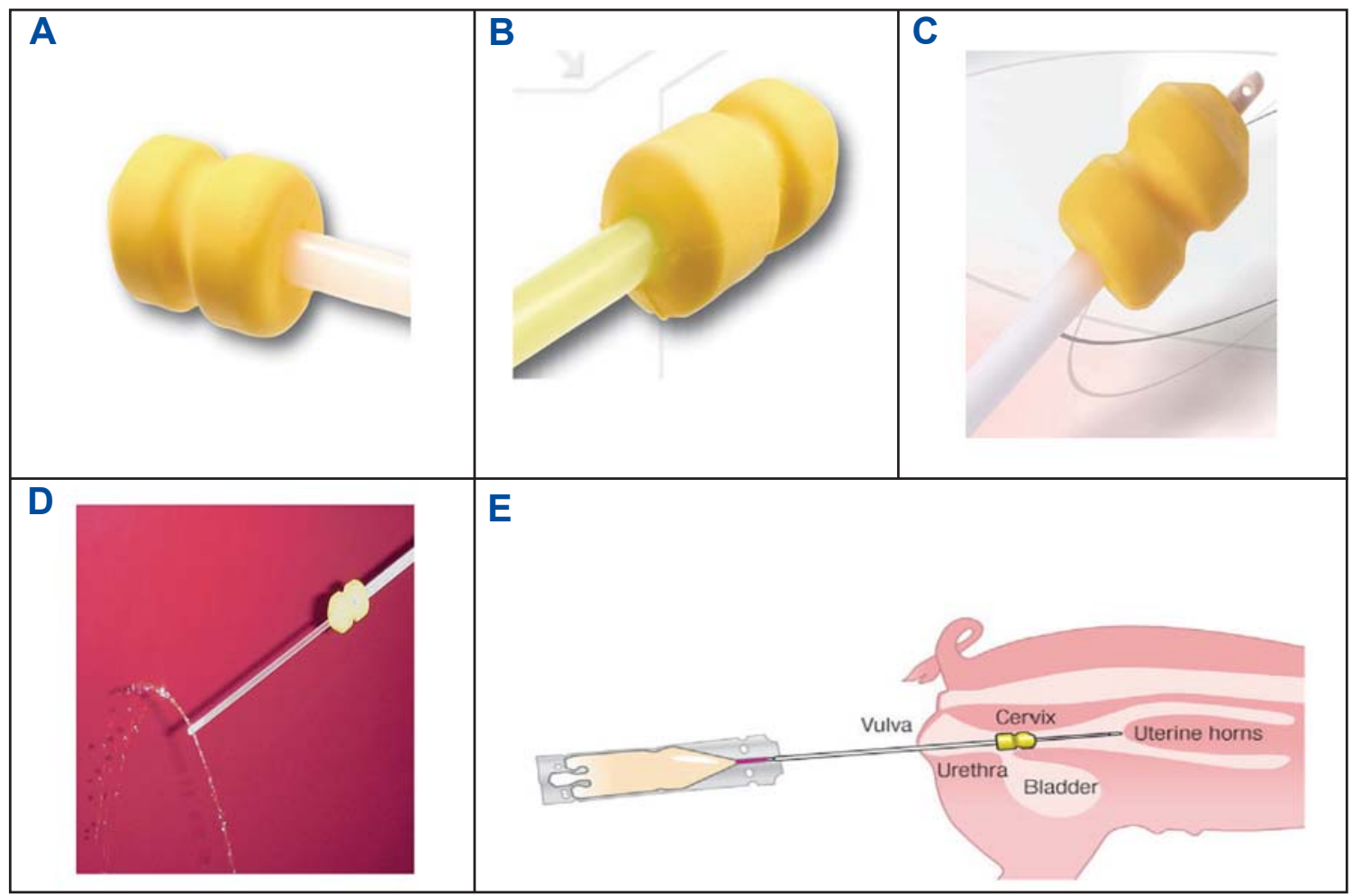

Figure 6. The polyurethane sponge tip of the conventional catheter (A) and the smaller tapered tip of the gilt catheter (B) for intracervical AI. The tip of the intrauterine catheter $(\mathbf{C})$ having two lateral orifices with semen emerging (D) during AI (E); adapted from IMV technologies (France) and Watson and Behan (89). 
yet standardized. It appears that the threshold dose for achieving a systematic high fertility success is at least $1 \times 10^{9}$ sperm. However, when farm condition or semen quality is suboptimal, it is prudent to use $1.5 \times 10^{9}$ spermatozoa per IUI dose $(11,85,195-198)$.

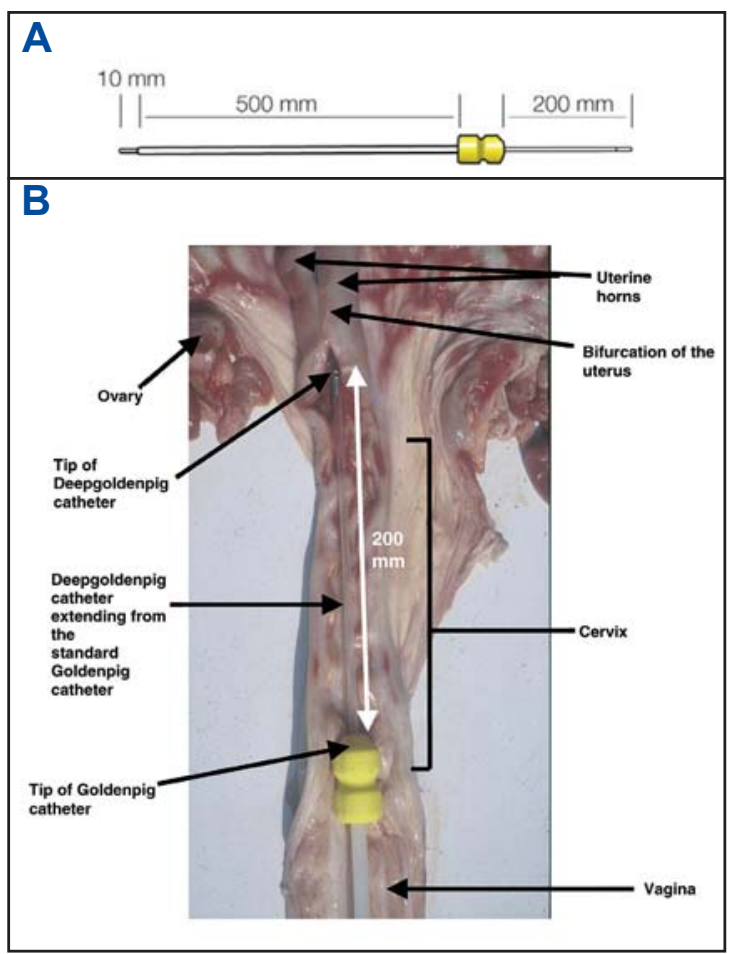

Figure 7. The full length of the intrauterine catheter "Deepgoldenpig ${ }^{\mathrm{TM}}$ " (A) at the stage of insemination in the reproductive tract of the sow $(\mathbf{B})$; adapted from IMV technologies (France) and Watson and Behan (89).

\section{DIUI with frozen-thawed semen}

To the authors' knowledge, few field trials have been published for evaluating the potential effectiveness of IUI with cryopreserved sperm, and fertility outcomes are not encouraging (11). Nonetheless, DIUI offers optimistic possibilities to an effective and efficient use of frozen-thawed semen $(194,196,198,200)$. In fixed-time AI protocols, a single DIUI close to the beginning of ovulation with $1 \times 10^{9}$ frozen-thawed spermatozoa ( 500-560x $10^{6}$ live sperm per dose) can achieve high fertility outcomes (farrowing rates over $80 \%$ with $>10$ piglets born per litter) $(11,201)$. Moreover, a second fixed-time AI or doubling sperm numbers in single fixed-time AI partially compensates some variations in the expected time of ovulation (11).

Different devices are available for DIUI (Fig. 10) without sedation of the animals (197). After thorough cleaning of the perineal area of the sows, an 24
AI spirette (Minitüb, Germany) is inserted through the vagina into the cervix and used to manipulate a specially designed flexible catheter (working length $1.80 \mathrm{~m}$, outer diameter $4 \mathrm{~mm}$, diameter of the inner tubing $1.8 \mathrm{~mm}$ ) (Fig. 10). The flexible catheter is then inserted through the spirette, passed through the cervical canal and moved forward along one uterine horn until its total length has been inserted. Before performing DIUI, the inner tubing of the flexible catheter is rinsed with BTS diluent and refilled with $\sim 2 \mathrm{ml}$ of BTS extender at $30^{\circ} \mathrm{C}$. The predetermined

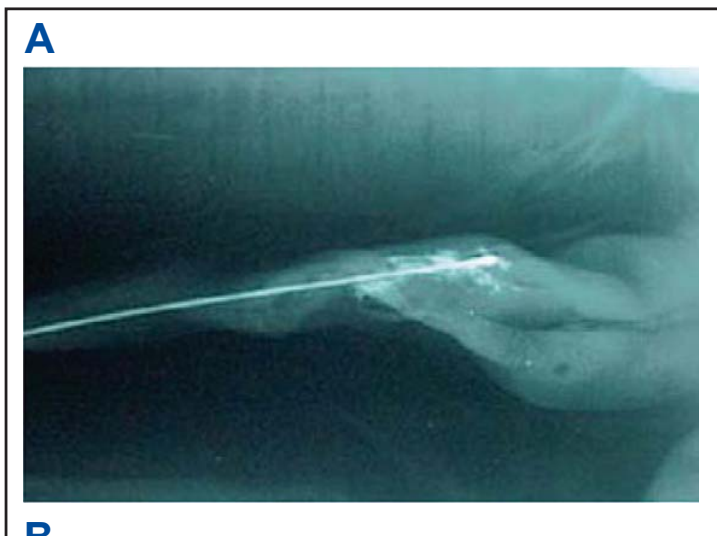

B
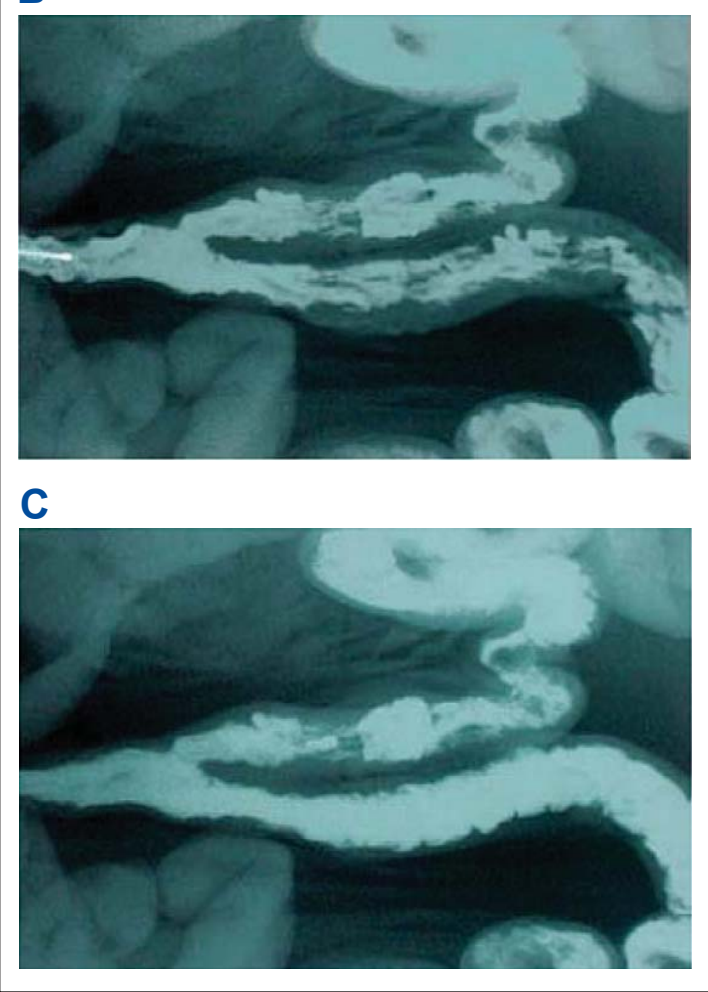

Figure 8. Radiographs of the intrauterine catheter at the beginning of insemination (A) and after 1 (B) and 2 (C) min of insemination; adapted from IMV technologies (France) 


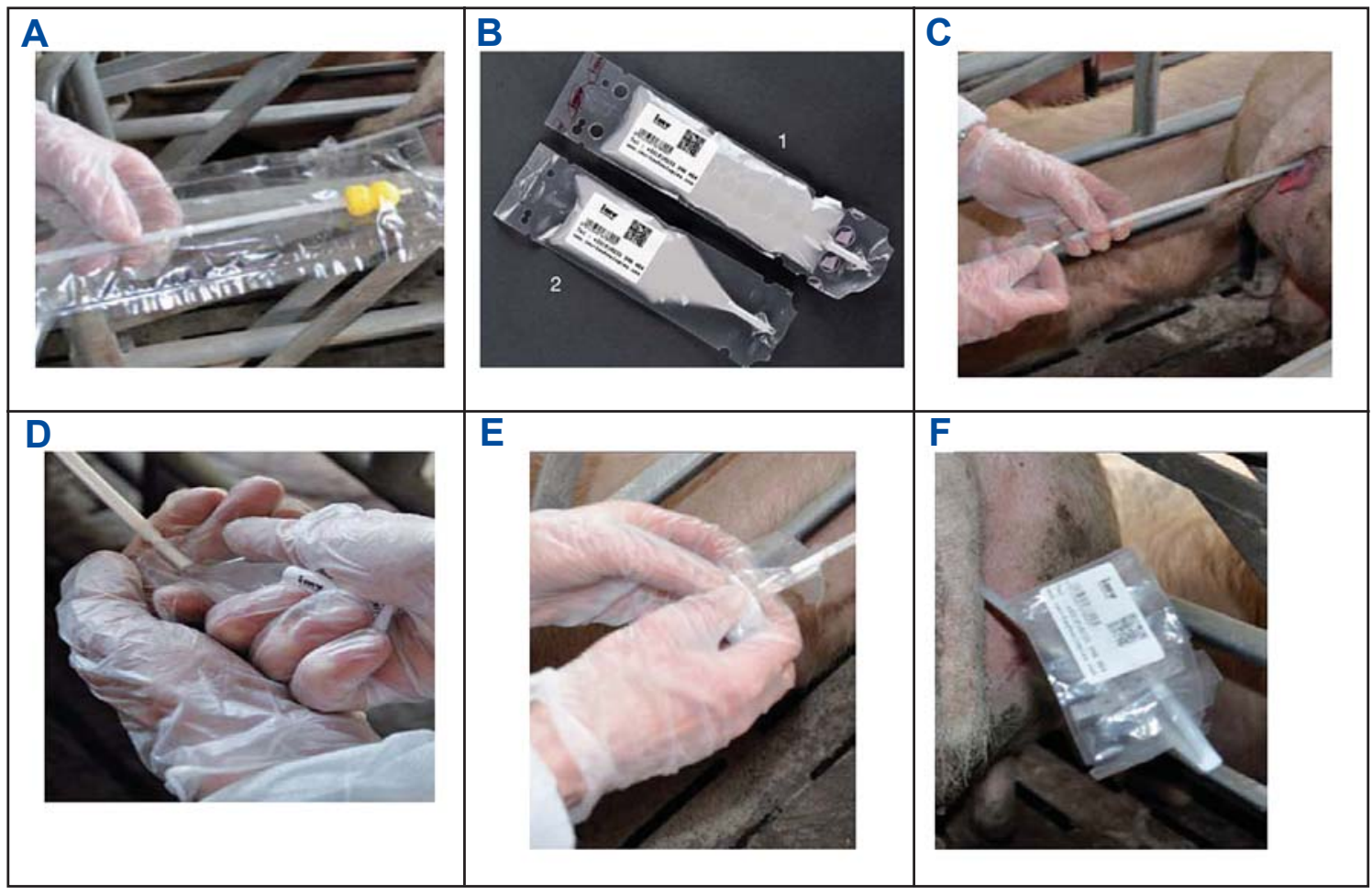

Figure 9. Procedures of intrauterine insemination of a sow which include removal of the Deepgoldenpig ${ }^{\mathrm{TM}}$ catheter from the plastic cover (A), bringing the semen doses in GTB bags $\left(80^{1}\right.$ and $40^{2} \mathrm{ml}$; B), careful insertion of the lubricated catheter in the genital tract $(\mathbf{C})$, direct connection of the semen bag to the catheter $(\mathbf{D})$ and discharging the semen by making a gentle pressure on the bag (E-F); adapted from IMV technologies (France).

insemination dose of spermatozoa in $5 \mathrm{ml}$ at $30^{\circ} \mathrm{C}$ is then infused into one uterine horn using a $5-\mathrm{ml}$ disposable syringe attached to the inner tubing of the flexible catheter. Subsequently, an additional $5 \mathrm{ml}$ of BTS extender is used to force all remaining spermatozoa out of the flexible catheter (197).

\section{A}

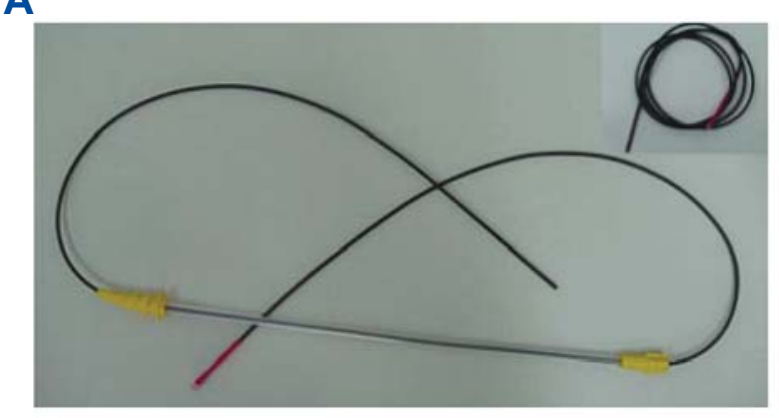

C

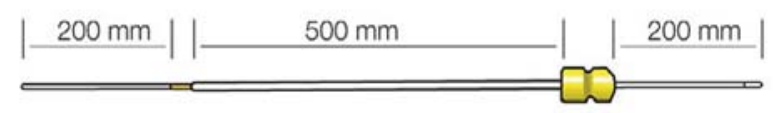

\section{B}

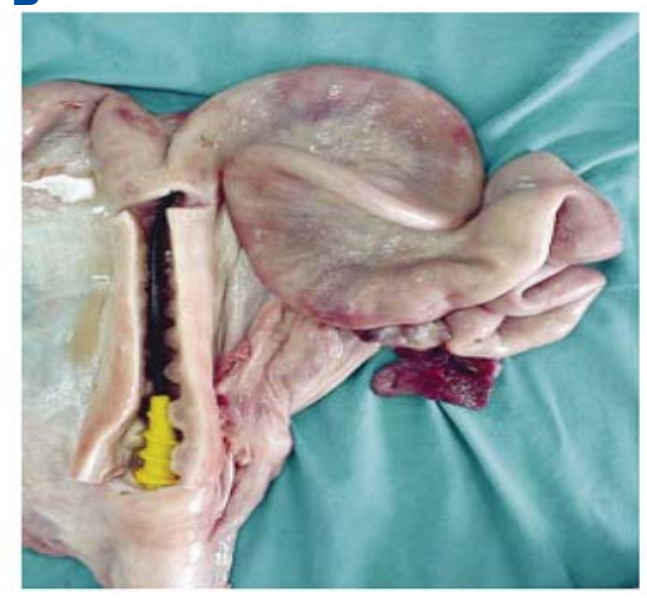

Figure 10. A flexible catheter used for deep intrauterine insemination with frozen-thawed boar semen (A), the silhouette of the catheter inserted into a uterine horn (B); adapted from Martinez et al. (197). A commercial device (GT Deep $^{\mathrm{TM}}$, IMV technologies) used for uterine horn insemination in sows (C). 


\section{CONCLUDING REMARKS}

The unique characteristics of boar sperm metabolism render AI in pigs more popular compared with other livestock species. The key to the widespread application of AI worldwide is the ability to preserve sperm fertility for up to a week at nearly room temperature, using simple procedures of semen collection, storage and AI. The use of sperm-rich fraction, holding of semen at $18^{\circ} \mathrm{C}$ and fortification of the storage extender with a combination of milk proteins and egg yolk emulsified in presence of Equex STM and BHT, can protect boar sperm during chilled storage at $5^{\circ} \mathrm{C}$; however, further studies are needed to evaluate fertility of chilled semen versus that of stored semen at $16-20^{\circ} \mathrm{C}$. In spite of the availability of freezing technology, frozen semen is not widely used in the commercial pig production, mainly because it is not as cost effective as liquid semen. Development of an efficient protocol for synchronizing the time of ovulation in sows and gilts coupled with improving DIUI technique will make a breakthrough in the commercial use of frozen semen. In order to improve fertility of liquid semen obtained from a subfertile terminal sire with good genetics, we suggest the following recommendations: (a) increase the hygienic standards during semen collection to minimize bacterial contamination of the ejaculate, (b) collect the sperm-rich fraction, (c) select the appropriate storage extender and treat the semen with antibiotics based on a bacterial resistance test, (d) select good quality spermatozoa through colloidal purification of semen, (e) add caffeinated media to semen doses just before AI, and (f) carefully deposit semen doses in the uterine body during AI.

\section{ACKNOWLEDGEMENT}

This work was supported by Nidacon International AB, Flöjelbergsgatan 16B, SE-431 37 Mölndal, Sweden (Project \# 1003-P; 2011-2012) and by the Veterinary Research Institute, Hellenic Agricultural Organization, 57001 NAGREF Campus, Thermi, P.O. Box 60272, Thessaloniki, Greece.

\section{REFERENCES}

1. Broekhuijse, M.L., Feitsma, H., Gadella B.M. (2012). Artificial insemination in pigs: predicting male fertility. Vet Q 32: 151-157.
2. Johnson, L.A., Weitze K.F., Fiser, P., Maxwell, W.M.C. (2000). Storage of boar semen. Anim Reprod Sci 62: 143-172.

3. Riesenbeck, A. (2011). Review on international trade with boar semen. Reprod Domest Anim 46 (Suppl. 2): 1-3.

4. Sigleton, W.L. (2001). State of the art in artificial insemination of pigs in the United States. Theriogenology 56: 1305-1310.

5. Knox, R., Levis, D., Safranski, T., Singleton, W. (2008). An update on North American boar stud practices. Theriogenology 70: 1202-1208.

6. Feitsma, H. (2009). Artificial insemination in pigs, research and developments in The Netherlands, a review. Acta Scientiae Veterinariae 37 (Suppl. 1): 61-71.

7. Broekhuijse, M.L.W.J., Feitsma, H., Gadella, B.M. (2011). Field data analysis of boar semen quality. Reprod Domest Anim 46 (Suppl. 2): 59-63.

8. Vyt, P., Maes, D., Rijsselaere, T., Dewulf, J., De Kruif, A., Van Soom, A. (2007). Semen handling in porcine AI centers: the Belgian situation. Vlaams Diegeneeskundig Tijdschrift 76: 195-199.

9. López Rodríguez, A., Rijsselaere, T., Vyt, P., Van Soom, A., Maes, D. (2012). Effect of dilution temperature on boar semen quality. Reprod Domest Anim 47: 63-66.

10. Martinez, E.A., Vazquez J.M., Roca, J., Cuello, C., Gil, M.A., Parrilla, I., Vazquez, J.L. (2005). An update on reproductive technologies with potential short-term application in pig production. Reprod Domest Anim 40: 300-309.

11. Roca, J., Parrilla, I., Rodriguez-Martinez, H., Gil, M.A., Cuello, C., Vazquez J.M., Martinez, E.A. (2011). Approaches towards efficient use of boar semen in the pig industry. Reprod Domest Anim 46 (Suppl. 2): 79-83.

12. Gadea, J. (2003). Review: semen extenders used in the artificial insemination of swine. Spanish J Agric Res 1 (2): 17-27.

13. Waberski, D., Henning, H., Petrunkina, A.M. (2011). Assessment of storage effects in liquid preserved boar semen. Reprod Domest Anim 46 (Suppl. 2): 45-48.

14. Goldberg,A.M.,Argenti, L.E., F accin, J.E., Linck, L., Santi, M., Bernardi, M.L., Cardoso, M.R., Wentz, I., Bortolozzo, F.P. (2013). Risk factors for bacterial contamination during boar semen collection. Res Vet Sci (In press), doi: 10.1016/j.rvsc.2013.06.022.

15. Dziuk, P.J., Henshaw, G. (1958). Fertility of boar semen artificially inseminated following in vitro storage. J Anim Sci 17: 554-558.

16. First, N.L., Stratman, F.W., Casida, L.E. (1963). Effect of sperm age on embryo survival in swine. $\mathrm{J}$ Anim Sci 22: 135-138. 
17. Pursel, V.G., Johnson, L.A., Schulman, L.L. (1973). Fertilizing capacity of boar semen stored at $15^{\circ} \mathrm{C}$. J Anim Sci 37: 532-535.

18. Bailey, J.L., Lessard, C., Jacques, J., Bréque, C., Dobrinski, I., Zeng, W., Galantino-Homer, H.L. (2008). Cryopreservation of boar semen and its future importance to the industry. Theriogenology 70: 1251-1259.

19. Großfeld, R., Sieg, B., Struckmann, C., Franzel, A., Maxwell, W.M.C., Rath, D. (2008). New aspects of boar semen freezing strategies. Theriogenology 70 : 1225-1233.

20. Knox, R.V. (2011). The current value of frozenthawed boar semen for commercial companies. Reprod Domest Anim 46 (Suppl. 2): 4-6.

21. Khalifa, T.A.A., Tsakmakidis, I.A. (2012). A preliminary study on preservability of porcine semen in INRA-96 extender. Proceeding of the $17^{\text {th }}$ International Congress on Biotechnology in Animal Reproduction (ICBAR), $12^{\text {th }}$ to $14^{\text {th }}$ September, Leipzig, Anhalt University of Applied Sciences, Germany.

22. Mozo-Martín, R., Gil, L., Gómez-Rincón, C.F., Dahmani, Y., García-Tomás, M., Úbeda, J.L., Grandía, J. (2012). Use of a novel double uterine deposition artificial insemination technique using low concentrations of sperm in pigs. Vet J 193: 251-256.

23. AAlbers, J.G., Mann, T., Polge, C. (1961). Metabolism of boar semen in relation to sperm motility and survival. J Reprod Fertil 2: 42-53.

24. Shelby, D.R., Foley, C.W. (1971). Influence of atmosphere and incubation temperature on the metabolism of washed boar spermatozoa. J Anim Sci 32: 103-106.

25. Jones, A.R. (1997). Metabolism of lactate by mature boar spermatozoa. Reprod Fertil Dev 9: 227-232.

26. Jones, A.R. (1997). Triosephosphate metabolism by mature boar spermatozoa. Reprod Fertil Dev 9: 577-581.

27. Jones, A.R., Connor, D.E. (2000). Fructose metabolism by mature boar spermatozoa. Reprod Fertil Dev 12: 355-359.

28. Marin, S., Chiang, K., Bassilian, S., Lee, W-N.P., Boros, L.G., Fernández-Novell, J.M., Centelles, J.J., Medrano, A., Rodriguez-Gil, J.E., Cascante, M. (2003). Metabolic strategy of boar spermatozoa revealed by a metabolomic characterization. FEBS Letters 554: 342-346.

29. Medrano, A., Fernández-Novell, J.MA., Ramió, L., Alvarez, J., Goldberg, E., Rivera, MA. M., Guinovart, J.J., Rigau, T., Rodríguez-Gil, J.E. (2006). Utilization of citrate and lactate through a lactate dehydrogenase and ATP-regulated pathway in boar spermatozoa. Mol Reprod Dev 73: 369-378.
30. White, I.G. (1993). Lipids and calcium uptake of sperm in relation to cold shock and preservation: a review. Reprod Fertil Dev 5: 639-658.

31. Galantino-Homer, H.L., Zeng, W-X., Omgee, S.O., Dallmeyer, M., Voelkl, D., Dobrinski, I. (2006). Effects of 2-hydroxypropyl- $\beta$-cyclodextrin and cholesterol on porcine sperm viability and capacitation status following cold shock or incubation. Mol Reprod Dev 73: 638-650.

32. Blanch, E., Tomás, C., Graham, J.K., Mocé, E. (2012). Response of boar sperm to the treatment with cholesterol-loaded cyclodextrins added prior to cryopreservation. Reprod Deomest Anim 47: 959-964.

33. Tomás, C., Blanch, E., Cebián, B., Mocé, E. (2013). In vivo fertilizing ability of frozen-thawed boar sperm treated with cholesterol-loaded cyclodextrins prior to cryopreservation. Anim Reprod Sci 140: 77-82.

34. Mann, T., Lutwak-Mann, C. (1981). Male reproductive function and semen. Themes and trends in physiology, biochemistry and investigative andrology. Springer-Verlag, Berlin, Heildelberg, New York.

35. Rodríguez-Martínez, H., Kvist, U., Saravia, F., Wallgren, M., Johannisson, A., Sanz, L., Peña, F.J., Martínez, E.A., Roca, J., Vázquez, J.M., Calvete, J.J. (2009). The physiological roles of the boar ejaculate. Soc Reprod Fertil Suppl. 66: 1-21.

36. Pursel, V.G., Johnson, L.A., Rampacek, G.B. (1972). Acrosome morphology of boar spermatozoa incubated before cold shock. J Anim Sci 34: 278-283.

37. Pursel, V.G., Johnson, L.A., Schulman, L.L. (1973). Effect of dilution, seminal plasma and incubation period on cold shock susceptibility of boar spermatozoa. J Anim Sci 37: 528-531.

38. Juarez,J.D.,Parrilla,I., Vazquez,J.M., Martinez,E.A., Roca, J. (2011). Boar semen can tolerate rapid cooling rates prior to freezing. Reprod Fertil Dev 23: 681-690.

39. Althouse, G.C., Wilson, M.E., Kuster,C., Parsley, M. (1998). Characterization of lower temperature storage limitations of fresh-extended porcine semen. Theriogenology 50: 535-543.

40. Paulenz, H., Kommisrud, E., Hofmo, P.O. (2000). Effect of long-term storage at different temperatures on the quality of liquid boar semen. Reprod Domest Anim 35: 83-87.

41. Mann, T. (1964). The biochemistry of semen and of the male reproductive tract. London: Mathuen \& Co LTD, New York: John Wiley \& Sons Inc.

42. Althouse, G.C., Pierdon, M.S., Lu, K.G. (2008). Thermotemporal dynamics of contaminant bacteria and antimicrobials in extended porcine semen. Theriogenology 70: 1317-1323. 
43. Schilling, E., Vengust, M. (1987). Frequency of semen collection in boars and quality of ejaculates as evaluated by the osmotic resistance of acrosomal membranes. Anim Reprod Sci 12: 283-290.

44. Arkins, S., Thomposon,L.H.,Giles, J.R., Camacho, T., Hosmon, B.D. (1988). The effect of collection procedure on the sperm output and copulatory behavior of AI stud boars. Anim Reprod Sci 16: 277-283.

45. Frangež, R., Gider,T., Kosec, M. (2005). Frequency of boar ejaculate collection and its influence on semen quality, pregnancy rate and litter size. Acta Vet Brno 74: 265-273.

46. Aneas, S.B., Gary, B.G., Bouvier, B.P. (2008). Collectis $^{\circledR}$ automated boar collection technology. Theriogenology 70: 1368-1373.

47. Thacker, B.J., Larsen, R.E., Joo, H.S., Leman, A.D. (1984). Swine diseases transmissible with artificial insemination. J Am Vet Med Assoc 185: 511-516.

48. Althouse, G.C., Kuster, C.E., Clark, S.G., Weisiger, R.M. (2000). Field investigations of bacterial contaminants and their effects on extended porcine semen. Theriogenology 53: 1167-1176.

49. Althouse, G.C., Kristina, G. Lu. (2005). Bacteriospermia in extended porcine semen. Theriogenology 63: 573-584.

50. Martín, L.O.M., Muñoz, , E.C., De Cupere, F., Van Driessche, E., Echemendia-Blanco, D., Rodríguez, J.M.M., Beeckmans, S. (2010). Bacterial contamination of boar semen affects the litter size. Anim Reprod Sci 120: 95-104.

51. Bussalleu, E., Yeste, M., Sepúlveda, L., Torner, E., Pinart, E., Bonet, S. (2011). Effects of different concentrations of enterotoxigenic and verotoxigenic E. coli on boar sperm quality. Anim Reprod Sci 127: 176-182.

52. Schautteet, K., De Clercq, E., Miry, C., Van Groenweghe, F., Delava, P., Kalmar,I., Vanrompay, D. (2013). Tetracycline-resistant Chlamydia suis in cases of reproductive failure on Belgian, Cypriote and Israeli pig production farms. J Med Microbiol 62 (Pt 2): 331-334.

53. Bamba, K., Sone, M. (1981). Factors affecting the quality of boar semen stored by means of dialysis. J Reprod Fert 62: 193-197.

54. Sone, M., Ohmura, K., Bamba, K. (1982). Effects of various antibiotics on the control of bacteria in boar semen. Vet Rec 111: 11-14.

55. Okazaki, T., Mihara, T., Fujita, Y., Yoshida, S., Teshima, H., Shimada, M. (2010). Polymixin B neutralizes bacteria-released endotoxin and improves the quality of boar sperm during liquid storage and cryopreservation. Theriogenology 74 : 1691-1700.
56. Waberski, D., Weitze, K.F., Meding, S., Leiding, C., Weiskopf, S. (1990) Examination on sperm and fertility compatibility of Lincospectin ${ }^{\circledR}$ sterile solution as antibiotic additive in liquid boar semen. Reprod Domest Anim 25: 291-295.

57. Morrell, J.M., Wallgren, M. (2011). Removal of bacteria from boar ejaculates by single layer centrifugation can reduce the use of antibiotics in semen extenders. Anim Reprod Sci 123: 64-69.

58. Morrell, J.M., Wallgren, M. (2011). Colloid centrifugation of boar semen. Reprod Domest Anim 46 (Suppl. 2): 18-22.

59. Rigau, T., Piedrafita, J., Reverter, A., Canal, M., Rodríguez-Gil, J.E. (1996). The rate of L-lactate production: a feasible parameter for the fresh boar semen quality analysis. Anim Reprod Sci 43: 161-172.

60. Kamp, G., Büsselmann, G., Jones, N., Wiesner, B., Lauterwein, J. (2003). Energy metabolism and intracellular $\mathrm{pH}$ in boar spermatozoa. Reproduction 126: 517-525.

61. Ford, W.C.L. (2006). Glycolysis and sperm motility: does a spoon of sugar help the flagellum go round? Hum Reprod Update 12: 269-274.

62. Vyt, P., Maes, D., Sys, S.U., Rijsselaere, T., Van Soom, A. (2007). Air contact influences the $\mathrm{pH}$ of extended porcine semen. Reprod Domes Anim 42: $218-220$

63. Storey, B.T. (2008). Mammalian sperm metabolism: oxygen and sugar, friend and foe. Int J Dev Biol 52: 427-437.

64. Bucci,D.,Isani,G.,Spinaci,M., Tamanini,C.,Mari,G., Zambelli, D., Galeati, G. (2010). Comparative immunolocalization of GLUTs 1, 2, 3 and 5 in boar, stallion and dog spermatozoa. Reprod Doest Anim 45: 365 .

65. Bucci, D., Rodriguez-Gil, J.E., Vallorani, C., Spinaci, M.,Galeati, G., Tamanini, C. (2011). GLUTs and mammalian sperm metabolism. J Androl 32: 348-355.

66. Purdy, P.H., Tharp, N., Stewart, T., Spiller, S.F., Blackburn, H.D. (2010). Implications of the $\mathrm{pH}$ and temperature of diluted, cooled boar semen on fresh and frozen-thawed sperm motility characteristics. Theriogenology 74: 1304-1310.

67. Bonet, S. (1990). Immature and aberrant spermatozoa in the ejaculate of Sus domesticus. Anim Reprod Sci 22: $67-80$.

67. Briz, M.D., Bonet, S., Pinart, B., Egozcue, J., Camps, R. (1995). Comparative study of boar sperm coming from the caput, corpus, and cauda regions of the epididymis. J Androl 16: 175-187.

69. Harayama,H., Shibukawa,T., Miyake,M.,Kannan,Y., Kato, S. (1996). Fructose stimulates shedding of cytoplasmic droplets from epididymal boar spermatozoa. Reprod Fertil Dev 8: 1039-1043. 
70. Vyt, P., Maes, D., Dejonckheere, E., Castryck, F., Van Soom, A. (2004). Comparative study on five different commercial extenders for boar semen. Reprod Domest Anim 39: 8-12.

71. Gilmore, J.A., Du, J., Tao, J., Peter, A.T., Critser, J.K. (1996). Osmotic properties of boar spermatozoa and their relevance to cryopreservation. J Reprod Fertil 107: 87-95.

72. Fraser, L., Gorszczaruk, K., Strzeźek, J. (2001). Relationship between motility and membrane integrity of boar spermatozoa in media varying in osmolality. Reprod Domest Anim 36: 325-329.

73. Yeste, M., Briz, M., Pinart, E., Sílvia, S., Bussalleu, E., Bonet, S. (2010). The osmotic tolerance of boar spermatozoa and its usefulness as sperm quality parameter. Anim Reprod Sci 119: 265-274.

74. Marcos, C.P., Sanchez, R., Palacio, M., Pursel, V.G., Garcia, T.P., Rillo, S.M. (1991). Effects of dilution rate on the motility and acrosome morphology of boar spermatozoa stored at $15^{\circ} \mathrm{C}$. Reprod Domest Anim 26: 112-116.

75. Maxwell, W.M.C., Johnson, L.A. (1999). Physiology of spermatozoa at high dilution rates: the influence of seminal plasma. Theriogenology 52: 1353-1362.

76. Harrison, R.A.P., Dott, H.M., Foster, G.C. (1978). Effect of ionic strength, serum albumin and other macromolecules on the maintenance of motility and the surface of mammalian spermatozoa in a simple medium. J Reprod Fert 52: 65-73.

77. Waberski, D., Meding, S., Dirksen, G., Weitze, K.F., Leiding, C., Hahn, R. (1994). Fertility of long-termstored boar semen: influence of extender (Androhep and Kiev), storage time and plasma droplets in the semen. Anim Reprod Sci 36: 145-151.

78. Dziuk, P.J., Henshaw, G. (1959). Fertility of boar semen artificially inseminated following in vitro storage. J Anim Sci 17: 554-558.

79. Baker, R.D., Dziuk, P.J., Norton, H.W. (1968). Effect of volume of semen, number of sperm and drugs on transport of sperm in artificially inseminated gilts. J Anim Sci 27: 88-93.

80. Johnson, L.A., Aalbers, J.G., Willems, C.M.T., Rademaker, J.H.M., Rexroad, C.E. Jr. (1982). Use of boar spermatozoa for artificial insemination III. Fecundity of boar spermatozoa stored in Beltsville liquid and Kiev extenders for three days at $18^{\circ} \mathrm{C}$. J Anim Sci 54: 132-136.

81. Johnson, L.A., Aalbers, J.G., Grooten, H.J.G. (1988). Artificial insemination of swine: fecundity of boar semen stored in Beltsville TS (BTS), modified modina (MM), or MA-A and inseminated on one, three and four days after collection. Zuchthyg 23: 49-55.

82. Waberski, D., Weitze, K.F., Lietmann, C., Lübbert zur Large, W., Bortolozzo, F.P., Willmen, T., Petzoldt, R. (1994). The initial fertilizing capacity of long term-stored liquid boar semen pre- and postovulatory insemination. Theriogenology 41: $1367-1377$.
83. Soede, N.M., Wetzels, C.C.H., Zondag, W., de Koning, M.A.I., Kemp, B. (1994). Effects of time of insemination relative to ovulation, as determined by ultrasonography, on fertilization rate and accessory sperm count in sows. J Reprod Fertil 104: 99-106.

84. Soede, N.M., Wetzels, C.C.H., Zondag, W., Hazeleger, W., Kemp, B. (1994). Effects of a second insemination after ovulation on fertilization rate and accessory sperm count in sows. J Reprod Fertil 105: 135-140.

85. Nissen, A.K., Soede, N.M., Hyttel, P., Schmidt, M., D'Hoore, L. (1997). The influence of time of insemination relative to time of ovulation on farrowing frequency and litter size in sows, as investigated by ultrasonography. Theriogenology 47: 1571-1582.

86. Steverink, D.W. B., Soede, N.M., Bouwman, E.G., Kemp, B. (1998). Semen backflow after insemination and its effect on fertilization results in sows. Anim Reprod Sci 54: 109-119.

87. Kuster, C.E., Althouse, G.C. (1999). The fecundity of porcine semen stored for 2 to 6 days in Androhep ${ }^{\circledR}$ and $\mathrm{X}-\mathrm{Ce} 1 \mathrm{~T}^{\mathrm{TM}}$ extenders. Theriogenology 52: 365376.

88. Foote, R.H. (2002). Within-herd use of boar semen at $5^{\circ} \mathrm{C}$, with a note on electronic monitoring of estrus. Reprod Domest Anim 37: 61-63.

89. Watson, P.F., Behan, J.R. (2002). Intrauterine insemination of sows with reduced sperm numbers: results of a commercially based field trial. Theriogenology 57: 1683-1693.

90. Haugan, T., Gaustad, A.H., Reksen, O., Gröhn, Y.T., Hofmo, P.O. (2007). Fertility results of artificial inseminations performed with liquid boar semen stored in X-Cell ${ }^{\mathrm{TM}}$ vs. BTS extender. Reprod Domest Anim 42: 94-99.

91. Wolf, J., Smital, J. (2009). Quantification of factors affecting semen traits in artificial insemination boars from animal model analyses. J Anim Sci 87: 1620-1627.

92. Stančić, B., Radović, I., Stančić, I., Dragin, S., Boźić, A., Gvozdić, D. (2010). Fertility of sows after intracervical or intrauterine insemination with different spermatozoa number in reduced volume doses. Acta Veterinaria (Beograd) 60: 257262.

93. Weitze, K.F., Wagner-Rietschel, H., Waberski, D., Richter, L., Krieter, J. (1994). The onset of heat after weaning, heat duration, and ovulation as major factors in AI timing in sows. Reprod Domest Anim 29: 433-443.

94. Koketsu, Y., Dial, G.D., King, V.L. (1997). Returns to service after mating and removal of sows for reproductive reasons from commercial swine farms. Theriogenology 47: 1347-1363.

95. de Kruif, A. (2003). Fertility and sterility in domestic animals. Verh K Geneeskd Bleg 65: 189202. 
96. Sancho, S., Pinart, E., Briz, M., Garcia-Gil, N., Badia, E., Bassols, J., Kádár, E., Pruneda, A., Bussalleu, E., Yeste, M., Coll, M.G., Bonet, S. (2004). Semen quality of postpubertal boars during increasing and decreasing natural photoperiods. Theriogenology 62: 1271-1282.

97. Einarsson, S., Brandt,Y., Lundeheim, N., Madej, A. (2008). Stress and its influence on reproduction in pigs: a review. Acta Vet Scand 50:48. doi: 10.1186/1751-0147-50-48 (http:// www.actavetscand.com/content/50/1/48).

98. Sonderman, J.P., Luebbe, J.J. (2008). Semen production and fertility issues related to differences in genetic lines of boars. Theriogenology 70: 1380-1383.

99. Huang, Y.H., Lo, L.L., Liu, S.H., Yang, T.S. (2010). Age-relating changes in semen quality characteristics and expectations of reproductive longevity in Duroc boars. Anim Sci J 81: 432-437.

100. Tsakmakidis, I.A., Khalifa, T.A.A., Boscos, C.M. (2012). Age-related changes in quality and fertility of porcine semen. Biol Res 45: 381-386.

101. Khalifa, T., Rekkas, C., Tsakmakidis, I., Zdragas,A., Samartzi, F., Lymberopulos, A. (2012). Long-term storage of porcine spermatozoa in chemically defined extenders. Reprod Domest Anim 47 (Suppl. 5): 91 (abstract P83).

102. Hood, R.D., Foley, C.W., Martin, T.G. (1970). Effects of cold shock, dilution, glycerol and dimethyl sulfoxide on cation concentrations in porcine spermatozoa. J Anim Sci 30: 91-94.

103. Watson, P.F. (1995). Recent development and concepts in the cryopreservation of spermatozoa and the assessment of their post-thawing function. Reprod Fertil Dev 7: 871-891.

104. Bamba, K., Cran, D.G. (1985). Effect of rapid warming of boar semen on sperm morphology and physiology. J Reprod Fert 75: 133-138.

105. Bamba, K., Cran, D.G. (1988). Further studies on rapid dilution and warming of boar semen. J Reprod Fert 82: 509-518.

106. Safranski,T.J.,Ford,J.J., Rohrer, G.A., Guthrie,H.D. (2011). Genetic selection for freezability and its controversy with selection for performance. Reprod Domest Anim 46 (Suppl. 2): 31-34.

107. Benson, R.W., Pickett, B.W., Komarek, R.J., Lucas, J.J. (1967). Effect of incubation and cold shock on motility of boar spermatozoa and their relationship to lipid content. J Anim Sci 35: 580-584.

108. Pursel, V.G., Johnson, L.A., Schulman, L.L. (1972). Interaction of extender composition and incubation period on cold shock susceptibility of boar spermatozoa. J Anim Sci 35: 580-584.

109. Tamuli, M.K., Watson, P.F. (1994). Cold resistance of live boar spermatozoa during incubation after ejaculation. Vet Rec 135: 160-162.
110. Eriksson, B.M., Vazquez, J.M., Martinez, E.A., Roca, J., Lucas, X., Rodriguez-Martinez, H. (2001). Effects of holding time during cooling and of type of package on plasma membrane integrity, motility and in vitro oocyte penetration ability of frozen-thawed boar spermatozoa. Theriogenology 55: 1593-1605.

111. Casas, I., Althouse, G.C. (2013). The protective effect of a $17^{\circ} \mathrm{C}$ holding time on boar sperm plasma membrane fluidity after exposure to $5^{\circ} \mathrm{C}$. Cryobiology 66: 69-75.

112. Berger, T., Clegg, E.D. (1985). Effect of male accessory gland secretions on sensitivity of porcine sperm acrosomes to cold shock, initiation of motility and loss of cytoplasmic droplets. J Anim Sci 60: 1295-1302.

113. Saravia, F. (2008). Cryopreservation of boar semen: impact of the use of specific ejaculate portions, concentrated packaging, and simplified freezing procedures on sperm cryosurvival and potential fertilizing capacity. Doctoral Thesis No. 2008:98, Swedish University of Agricultural Sciences, Faculty of Veterinary Medicine and Animal Science, Division of Reproduction, Department of Clinical Sciences, Uppsala, Sweden.

114. Guthrie, H.D., Welch, G.R. (2005). Impact of storage prior to cryopreservation on plasma membrane function and fertility of boar sperm. Theriogenology 63: 396-410.

115. Garcia, J.C., Dominquez, J.C., Pena, F.J., Alegre, B., Gonzalez, R., Castro, M.J., Habing, G.G., Kirkwood, R.N. (2010). Thawing boar semen in the presence of seminal plasma: effects on sperm quality and fertility. Anim Reprod Sci 119: 160-165.

116. Leahy, T., Gadella, B.M. (2011). Capacitation and capacitation-like sperm surface changes induced by handling boar semen. Reprod Domest Anim 46 (Suppl. 2): 7-13.

117. Gómez-Fernández, J., Gómez-Izquierdo, E., Tomás, C., González-Bulnes, A., SánchezSánchez, R., de Mercado, E. (2012). Inclusion of seminal plasma in sperm cryopreservation of Iberian pig. Anim Reprod Sci 130: 82-90.

118. Okazaki, T., Akiyoshi, T., Kan, M., Mori, M., Teshima, H., Shimada, M. (2012). Artificial insemination with seminal plasma improves the reproductive performance of frozen-thawed boar epididymal spermatozoa. J Androl 33: 990-998.

119. Okazaki, T., Shimada, M. (2012). New strategies of boar sperm cryopreservation: development of novel freezing and thawing methods with a focus on the roles of seminal plasma. Anim Sci J 83: 623-629.

120. Fernández-Gago, R., Domínguez, J.C., MartínezPastor, F. (2013). Seminal plasma applied postthawing affects boar sperm physiology: a flow cytometry study. Theriogenology 80: 400-410. 
121. Khalifa, T.A.A., Tsakmakidis, I.A., Michos, I.A., Rekkas, C.A. (2011). Effect of semen processing procedures on quality of cooled boar spermatozoa. Reprod Domest Anim 46 (Suppl. 2): 95-96 (abstract P15).

122. Batellier, F., Magistrini, M., Fauquant, J., Palmer, E. (1997). Effect of milk fractions on survival of equine spermatozoa. Theriogenology 48 : 391-410.

123. Vishwanath, R., Shannon, P. (2000). Storage of bovine semen in liquid and frozen state. Anim Reprod Sci 62: 23-53.

124. Salamon, S., Maxwell, W.M.C. (2000). Storage of ram semen. Anim Reprod Sci 62: 77-111.

125. Leboeuf, B., Restall, B., Salamon, S. (2000). Production and storage of goat semen for artificial insemination. Anim Reprod Sci 62: 113-141.

126. Gutiérrez-Cepeda, L., Fernández, Á., Crespo, F., Ramírez, M. Á., Gosálvez, J., Serres, C. (2012). The effect of two pre-cryopreservation single layer colloidal centrifugation protocols in combination with different freezing extenders on the fragmentation dynamics of thawed equine sperm DNA. Acta Vet Scand 54: 72, doi: 10.1186/17510147-54-72.

127. Butler, W.J., Roberts, T.K. (1975). Effects of some phosphatidyl compounds on boar spermatozoa following cold shock or slow cooling. J Reprod Fert 43: 183-187.

128. Pursel, V.G., Johnson, L.A. (1975). Freezing of boar spermatozoa: fertilizing capacity with concentrated semen and a new thawing procedure. J Anim Sci 40: 99-102.

129. Pursel, V.G., Schulman, L.L., Johnson, L.A. (1978). Effect Orvus ES Paste on acrosome morphology. motility and fertilizing capacity of frozen-thawed boar sperm. J Anim Sci 47: 198-202.

130. Graham, E.F., Crabo, B.G., Pace, M.M. (1978). Current status of semen preservation in the ram, boar and stallion. J Anim Sci 47 (Suppl. 2): 80-119.

131. Pursel, V.G., Schulman, L.L., Johnson, L.A. (1978). Effect of glycerol concentration on frozen boar sperm. Theriogenology 9: 305-312.

132. Pursel, V.G. (1979). Effect of cold shock on boar sperm treated with butylated hydroxytoluene. Biol Reprod 21: 319-324.

133. Bamba, K., Cran, D.G. (1992). Effects of treatment with butylated hydroxytoluene on the susceptibility of boar spermatozoa to cold stress and dilution. J Reprod Fert 95: 69-77.

134. Bamba, K., Miyagawa, N. (1992). Protective action of aromatic compounds against cold-shock injuries in boar spermatozoa. Cryobiology 29: 533-536.
135. Roca, J., Gil, M.A., Hernandez, M., Parrilia, I., Vazquez, J.M., Martinez, E.A. (2004). Survival and fertility of boar spermatozoa after freezethawing in extender supplemented with butylated hydroxytoluene. J Androl 25: 397-405.

136. Khalifa, T.A.A., El-Saidy, B.E. (2006). Pelletfreezing of Damascus goat semen in a chemically defined extender. Anim Reprod Sci 93: 303-315.

137. Khalifa, T.A.A., Lymberopoulos, A.G., El-Saidy, B.E. (2008). Testing usability of butylated hydroxytoluene in conservation of goat semen. Reprod Domest Anim 43 : 525-530.

138. Hammerstedt, R.H., Keith, A.D., Snipes, W., Amann, R.P., Arruda, D., Griel, L.C. (1978). Use of spin labels to evaluate effects of cold shock and osmolality on sperm. Biol Reprod 18: 686-696.

139. Parks, J.E., Graham, J.K. (1992). Effects of cryopreservation procedures on sperm membranes. Theriogenology 38: 209-222.

140. Demianowicz, W., Strzezek, J. (1995). The effect of lipoprotein fraction from egg yolk on some of the biological properties of boar spermatozoa during storage of the semen in liquid state. Reprod Domest Anim 31: 279-280.

141. Jiang, Z-I., Li, Q-w., Hu, J-h., W-y., Zhao, H-w., Zhang, S-s. (2007). Improvement of the quality of boar cryopreservation semen by supplementing with low density lipoprotein in diluents. Cryobiology 54: 301-304.

142. Hu, J-h., Li, Q-w., Jiang, Z-I., Li, W-y. (2008). Effects of different extenders on DNA integrity of boar spermatozoa following freezing-thawing. Cryobiology 57: 257-262.

143. Yamauchi, S., Nakamura, S., Lay, K.M., Azuma, T., Yakabi, T., Muto, N., Nakada, T., Ashizawa, K., Tatemoto, H. (2009). Characteristics of Okinawan native Agu pig spermatozoa after addition of lowdensity lipoprotein to freezing extender. J Reprod Dev 55: 558-565.

144. Wang, P., Wang, Y.F., Wang, C.W., Bu, S.H., Li, Q.W., Pang, W.J., Yang, G.S. (2012). Effects of low-density lipoproteins extracted from different avian yolks on boar spermatozoa quality following freezing-thawing. Zygote 30: 1-7.

145. Zhang, S-S., Hu, J-H., Li, Q-W., Jiang, Z-L., Zhang, X-Y. (2009). The cryoprotective effects of soybean lecithin on boar spermatozoa quality. African J Biotech 8: 6476-6480.

146. Namula, Z., Sato, Y., Kodama, R., Morinaga, K., Luu, V.V., Taniguchi, M., Nakai, M., Tanihara, F., Kikuchi, K., Nagai, T., Otoi, T. (2013). Motility and fertility of boar semen after liquid preservation at $5^{\circ} \mathrm{C}$ for more than 2 weeks. Anim Sci J 84: 600-606. 
147. Almlid, T., Johnson, L.A. (1988). Effect of glycerol concentration, equilibration time and temperature of glycerol addition on post-thaw viability of boar spermatozoa frozen in straws. J Anim Sci 66: 2899-2905.

148. Fiser, P.S., Fairfull, R.W., Panich, P.L. (1996). Glycerol equilibration time revisited. Reprod Domest Anim 31 (1): 141-146.

149. Fiser, P.S., Fairfull, R.W. (1990). Combined effect of glycerol concentration and cooling velocity on motility and acrosomal integrity of boar spermatozoa frozen in $0.5 \mathrm{ml}$ straws. Mol Reprod Dev 25: 123-129.

150. Morris, G.J., Acton, E., Murray, B.J., Fonseca, F. (2012). Freezing injury: the special case of the sperm cell. Cryobiology 64: 71-80.

151. Mazur, P. (1985). Basic concepts in freezing cells. Proceeding of the $1^{\text {st }}$ International Conference on DeepFreezingofBoarSemen. SwedishUniversity of Agriculture Sciences, Uppsala, Sweden, pp. 91-111.

152. Mazur, P., Leibo, S.P., Seidel Jr., E. (2008). Cryopreservation of the germplasm of animals used in biological and medical research: importance, status, and future implications. Biol Reprod 78: $2-12$.

153. Wessel, M.T., Ball, B.A. (2004). Step-wise dilution for removal of glycerol from fresh and cryopreserved equine spermatozoa. Anim Reprod Sci 84: 147-156.

154. Burnaugh, L., Ball, B.A., Sabeur, K., Thomas, A.D., Meyers, S.A. (2010). Osmotic stress stimulates generation of superoxide anion by spermatozoa in horses. Anim Reprod Sci 117: 249-260.

155. Baumber, J., Vo, A., Sabeur, K., Ball, B.A. (2002). Generation of reactive oxygen species by equine neutrophils and their effect on motility of equine spermatozoa. Theriogenology 57: 1025-1033.

156. Broekhuijse, M.L.W.J., Feitsma, H., Gadella, B.M. (2012). Field data analysis of boar semen quality. Reprod Domest Anim 46 (Suppl. 2): 59-63.

157. Young, L.G., King, G.L. (1986). Low concentrations of zearalenone in diets of boars for a prolonged period of time. J Anim Sci 63: 1197-1200.

158. Solti, L., Pécsi, T., Barna-Vetró, I., Szász, F.Jr., Biró, K., Szabó, E. (1999). Analysis of serum and seminal plasma after feeding ochratoxin A with breeding boars. Anim Reprod Sci 56: 123-132.

159. Biró, K., Barna-Vetró, I., Pécsi, T., Szabó, E., Winkler, G., Fink-Gremmels, J., Solti, L. (2003). Evaluation of spermatological parameters in ochratoxin A-challenged boars. Theriogenology 60: 199-207.

160. Tsakmakidis, I.A., Lymberopoulos, A.G., Alexopoulos, C., Boscos, C.M., Kyriakis, S.C. (2006). In vitro effect of zearalenone and alphazearalenone on boar sperm characteristics and acrosome reaction. Reprod Domest Anim 41: 394-401.
161. Tsakmakidis,I.A.,Lymberopoulos,A.G., Vainas, E., Boscos, C.M., Kyriakis, S.C., Alexopoulos, C. (2007). Study on the in vitro effect of zearalenone and alpha-zearalenone on boar spermzona pellucida interaction by hemizona assay application. J Appl Toxicol 27: 498-505.

162. Tsakmakidis, I.A., Lymberopoulos, A.G., Khalifa, T.A.A., Boscos, C.M., Saratsi, A., Alexopoulos, C. (2008). Evaluation of zearalenone and alpha-zearalenone toxicity on boar sperm DNA integrity. J Appl Toxicol 28: 681-688.

163. Thibier, M., Guerin, B. (2000). Hygienic aspects of storage and use of semen for artificial insemination. Anim Reprod Sci 62: 233-251.

164. Bielanski, A. (2007). Disinfection procedures for controlling microorganisms in the semen and embryos of humans and farm animals. Theriogenology 68: 1-22.

165. Althouse, G.C., Rossow, K. (2011). The potential risk of infectious disease dissemination via artificial insemination in swine. Reprod Domest Anim 46 (Suppl. 2): 64-67.

166. Bussalleu, E., Pinart, E., Rivera, M.M., Arias, X., Briz, M., Sancho, S., García-Gil, N., Bassols, J., Pruneda, A., Yeste, M., Casas, I., Rigau, T., Rodriguez-Gil, J.E., Bonet, S. (2008). Effects of filtration of semen doses from subfertile boars through neuter sephadex columns. Reprod Domest Anim 43: 48-52.

167. Morrell, J.M., Saravia, F., Van Wienen, M., Wallgren, M., Rodriguez-Martinez, H. (2009). Selection of boar spermatozoa using centrifugation on a glycidoxypropyltrimethoxysilane-coated silica colloid. J Reprod Dev 55: 547-552.

168. Morrell, J.M., Saravia, F., Van Wienen, M., Wallgren, M., Rodriguez-Martinez, H. (2009). Sperm survival following colloid centrifugation varies according to the part of the sperm-rich fraction used. Soc Reprod Fertil Suppl 66: 85-86.

169. Ramió-LIuch, L., Balasch, S., Bonet, S., Briz, M., Pinart, E., Rodríguez-Gil, J. E. (2009). Effects of filtration through sephadex columns improve overall quality parameters and "in vivo" fertility of subfertile refrigerated boar-semen. Anim Reprod Sci 115: 189-200.

170. Blomqvist, G., Persson, M., Wallgren, M., Wallgren, P., Morrell, J.M. (2011). Removal of virus from boar semen spiked with porcine circovirus type 2. Anim Reprod Sci 126: 108-114.

171. Holt, W.V., Van Look, K.J.W. (2004). Concepts in sperm heterogeneity, sperm selection and sperm competition as biological foundations for laboratory tests of semen quality. Reproduction 127: $527-535$.

172. Pertoft, H., Laurent, T.C., Låås, T., Kågedal, L. (1978). Density gradients prepared from colloidal silica particles coated by polyvinylpyrrolidone (Percoll). Anal Biochem 88: 271-282. 
173. Rodriguez-Martinez, H., Larsson, B., Pertoft, H. (1997). Evaluation of sperm damage and techniques for sperm clean-up. Reprod Fertil Dev 9: 297-308.

174. Mortimer, D. (2000). Sperm preparation methods. J Androl 21: 357-366.

175. Henkel, R.R., Schill, W-B. (2003). Sperm preparation for ART. Reprod Biol Endocrinol 1: 108 (http://www.rbej.com/content/1/1/108).

176. Morrell, J.M., Rodriguez-Martinez, H. (2009). Biomimetic techniques for improving sperm quality in animal breeding: a review. The Open Andrololgy Journal 1: 1-9 (Bentham open access).

177. Morrell, J.M., Rodriguez-Martinez, H. (2010). Practical applications of sperm selection techniques as a tool for improving reproductive efficiency. Veterinary Medicine International, volume 2011, article ID 894767, SAGE-Hindawi access to research (doi: 10.4061/2011/894767).

178. Vanderwall, D.K. (2008). How to process a dilute ejaculate of semen for cooled-transported insemination. Proceedings of the $54^{\text {th }}$ Annual Convention of the American Association of Equine Practitioners, Dec 6-10, San Diego, California, Vol. 54, pp. 369-373.

179. Matthijs, A., Harkema, W., Engel, B., Woelders, H. (2000). In vitro phagocytosis of boar spermatozoa by neutrophils from peripheral blood of sows. J Reprod Fertil 120: 265-273.

180. Matthijs, A., Engel, B., Woelders, H. (2003). Neutrophil recruitment and phagocytosis of boar spermatozoa after artificial insemination of sows, and the effects of inseminate volume, sperm dose and specific additives in the extender. Reproduction 125: 357-367.

181. Oh, S.A., Park, Y.J., You, Y.A., Mohamed, E. A., Pang, M.G. (2010). Capacitation status of stored boar spermatozoa is related to litter size of sows. Anim Reprod Sci 121:131-138.

182. Horrigan, L.A.,Kelly, J.P., Connor, T.J. (2004). Caffeine suppresses TNF- $\alpha$ production via activation of the cyclic AMP/protein kinase A pathway. Int J Immunopharmacol 4: 1409-1417.

183. Horrigan, L.A.,Kelly, J.P., Connor, T.J. (2009). Immunomodulatory effects of caffeine: Friend or foe? Pharmacol Ther 111: 877-892.

184. Yeste, M., Briz, M., Pinart, E., Sancho, S., GarciaGil, N., Badia, E., Bassols, J., Pruneda, A., Bussalleu, E., Casas, I., Bonet, S. (2008). Hyaluronic acid delays boar sperm capacitation after 3 days of storage at $15^{\circ} \mathrm{C}$. Anim Reprod Sci 109: $236-250$

185. Martecikova,S.,Hulinska,P.,Reckova,Z.,Pavlik,A., Jeseta, M., Machatkova, M. (2010). Effect of acrosome reaction progress in frozen-thawed boar spermatozoa on the efficiency of in vitro oocyte fertilization. Veterinarni Medicina, 55: 429-437.
186. Yamaguchi, S., Suzuki, C., Noguchi, M., Kasa, S., Mori, M., Isozaki, Y., Ueda, S., Funahashi, H., Kikuchi, K., Nagai, T., Yoshioka, K. (2013). Effects of caffeine on sperm characteristics after thawing and inflammatory response in the uterus after artificial insemination with frozen-thawed boar semen. Theriogenology 79: 87-93.

187. Li,J.-C., Yamaguchib,S.,Kondoa,Y.,Funahashia,H. (2011). Caffeine, dibutyryl cyclic-AMP and heparin affect the chemotactic and phagocytotic activities of neutrophils for boar sperm in vitro. Theriogenology 75:1336-1345.

188. Li,J.-C.,Yamaguchib,S.,Kondoa,Y.,Funahashia,H. (2012). Boar seminal plasma or hen's egg yolk decrease the in vitro chemotactic and phagocytotic activities of neutrophils when co-incubated with boar or bull sperm. Theriogenology 77: 73-80.

189. Jiwakanon, J., Persson, E., Berg, M., Dalin, A.M. (2011). Influence of seminal plasma, spermatozoa and semen extender on cytokine expression in the porcine endometrium after insemination. Anim Reprod Sci 123:210-220.

190. Katila, T. (2012). Post-mating inflammatory responses of the uterus. Reprod Domest Anim 47 (Suppl. 5): 31-41.

191. Langendijk, P., Soede, N.M., Kemp, B. (2005). Uterine activity, sperm transport, and the role of boar stimuli around insemination in sows. Theriogenology 63: 500-513.

192. Yamaguchi, S., Funahashi, H., Murakami, T. (2009). Improved fertility in gilts and sows after artificial insemination of frozen-thawed boar semen by supplementation of semen extender with caffeine and $\mathrm{CaCl}_{2}$. J Reprod Dev 55: 645-649.

193. Yamaguchi, S., Funahashi, H. (2012). Effect of the addition of beta-mercaptoethanol to a thawing solution supplemented with caffeine on the function of frozen-thawed boar sperm and on the fertility of sows after artificial insemination. Theriogenology 77: 926-932.

194. Vazquez, J.M., Roca, J., Gil, M.A., Cuello, C., Parrilla, I., Vazquez, J.L., Martínez, E.A. (2008). New developments in low-dose insemination technology. Theriogenology 70: 1216-1224.

195. Watson, P.F., Behan, J.R. (2006). A field investigation of intra-cervical insemination with reduced sperm numbers in gilts. Theriogenology 66:338-343.

196. Martinez, E.A.,Vazquez, J.M., Roca, J., Lucas, X., Gil, M.A., Parrilla, I., Vazquez, J.L., Day, B.N. (2001). Successful non-surgical deep intrauterine insemination with small numbers of spermatozoa in sows. Reproduction 122: 289-296.

197. Martinez, E.A.,Vazquez, J.M., Roca, J., Lucas, X., Gil, M.A., Parrilla, I., Vazquez, J.L., Day, B.N. (2002). Minimum number of spermatozoa required for normal fertility after deep intrauterine insemination in non-sedated sows. Reproduction 123: $163-170$ 
198. Vazquez, J.M., Roca, J., Gil, M.A., Cuello, C., Parrilla, I., Vazquez, J.L., Martínez, E.A. (2008). Low-dose insemination in pigs: problems and possibilities. Reprod Domes Anim 43 (Suppl. 2): 347-354.

199. Spencer, K.W. (2010). Factors affecting fertility of frozen-thawed boar sperm. M.S. Thesis, University of Illinois at Urbana-Champaign, Illinois, USA (http://hdl.handle.net/2142/16492).
200. Vazquez, J.M., Martínez, E.A., Roca, J., Gil, M.A., Parrilla, I., Cuello, C., Carvajal, G., Lucas, X., Vazquez, J.L. (2005). Improving the efficiency of sperm technologies in pigs: the value of deep intrauterine insemination. Theriogenology 63: 536-547.

201. Spencer, K.W., Purdy, P.H., Blackburn, H.D., Spiller, S.F., Stewart, T.S., Knox, R.V. (2010). Effect of number of motile, frozen-thawed boar sperm and number of fixed-time inseminations on fertility in estrous-synchronized gilts. Anim Reprod Sci 121: 259-266. 